\title{
$\alpha$-Synuclein interacts with the switch region of Rab8a in a Ser129 phosphorylation-dependent manner
}

\author{
Guowei Yin $^{\mathrm{a}, 1}$, Tomas Lopes da Fonseca ${ }^{\mathrm{d}, \mathrm{e}, 1}$, Sibylle E. Eisbach ${ }^{\mathrm{d}, \mathrm{e}}$, Ane Martín Anduaga ${ }^{\mathrm{i}}$, Carlo Breda ${ }^{\mathrm{i}}$, \\ Maria L. Orcellet ${ }^{\mathrm{f}}$, Éva M. Szegő ${ }^{\mathrm{d}, \mathrm{e}}$, Patricia Guerreiro ${ }^{\mathrm{d}, \mathrm{e}}$, Diana F. Lázaro ${ }^{\mathrm{d}, \mathrm{e}}$, Gerhard H. Braus ${ }^{\text {c,e }}$, \\ Claudio O. Fernandez ${ }^{\text {, }}$ Christian Griesinger a , Stefan Becker a , Roger S. Goody ${ }^{\text {h }}$, Aymelt Itzen ${ }^{\text {g,h }}$, \\ Flaviano Giorgini ${ }^{i}$, Tiago F. Outeiro ${ }^{\text {d,e,* }}$, Markus Zweckstetter ${ }^{\text {a,b,e,* }}$ \\ a Department of NMR-based Structural Biology, Max Planck Institute for Biophysical Chemistry, Göttingen, Germany \\ ${ }^{\mathrm{b}}$ German Center for Neurodegenerative Diseases (DZNE), D-37077 Göttingen, Germany \\ c Dept. Molecular Microbiology and Genetics, Institute of Microbiology E' Genetics, Georg-August-Universität Göttingen, D-37077 Göttingen, Germany \\ d Department of Neurodegeneration and Restorative Research, University Medicine Göttingen, Göttingen, Germany \\ e DFG Research Center Nanoscale Microscopy and Molecular Physiology of the Brain (CNMPB), Göttingen, Germany \\ ${ }^{\mathrm{f}}$ Max Planck for Structural Biology, Chemistry and Molecular Biophysics of Rosario (MPLbioR), Universidad Nacional de Rosario, IBR-CONICET, Ocampo y Esmeralda, 2000 Rosario, Argentina \\ g Center for Integrated Protein Science Munich, Chemistry Department, Technische Universität München, Lichtenbergstr. 4, 85748 Garching, Germany

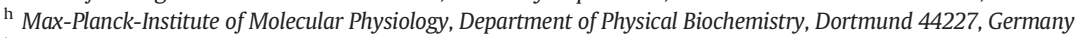 \\ i Department of Genetics, University of Leicester, Leicester LE1 7RH, UK
}

\section{A R T I C L E I N F O}

\section{Article history:}

Received 5 March 2014

Revised 16 June 2014

Accepted 22 June 2014

Available online 28 June 2014

\section{Keywords:}

$\alpha$-Synuclein

Aggregation

Parkinson's disease

Phosphorylation

Rab GTPase

\begin{abstract}
A B S T R A C T
Alpha-synuclein $(\alpha S)$ misfolding is associated with Parkinson's disease (PD) but little is known about the mechanisms underlying $\alpha S$ toxicity. Increasing evidence suggests that defects in membrane transport play an important role in neuronal dysfunction. Here we demonstrate that the GTPase Rab8a interacts with $\alpha S$ in rodent brain. NMR spectroscopy reveals that the C-terminus of $\alpha \mathrm{S}$ binds to the functionally important switch region as well as the C-terminal tail of Rab8a. In line with a direct Rab8a/ $\alpha$ S interaction, Rab8a enhanced $\alpha \mathrm{S}$ aggregation and reduced $\alpha$ S-induced cellular toxicity. In addition, Rab8 - the Drosophila ortholog of Rab8a - ameliorated $\alpha S$-oligomer specific locomotor impairment and neuron loss in fruit flies. In support of the pathogenic relevance of the $\alpha$ S-Rab8a interaction, phosphorylation of $\alpha \mathrm{S}$ at S129 enhanced binding to Rab8a, increased formation of insoluble $\alpha S$ aggregates and reduced cellular toxicity. Our study provides novel mechanistic insights into the interplay of the GTPase Rab8a and $\alpha \mathrm{S}$ cytotoxicity, and underscores the therapeutic potential of targeting this interaction.
\end{abstract}

(c) 2014 Elsevier Inc. All rights reserved.

\section{Introduction}

$\alpha$-Synuclein $(\alpha S)$ is a widely abundant protein in the central nervous system (Jakes et al., 1994; Iwai et al., 1995). Multiplications of the SNCA gene, which encodes $\alpha$ S (Chartier-Harlin et al., 2004), as well as point mutations in $\alpha \mathrm{S}$ cause autosomal dominant forms of Parkinson's disease (PD) (Hardy et al., 2009), a disease that affects several brain areas during its progression (Braak et al., 2003). In addition, insoluble aggregated $\alpha \mathrm{S}$ is the major component of Lewy bodies (Spillantini et al., 1997). During the last decade a growing body

\footnotetext{
* Corresponding authors.

E-mail addresses: tiago.outeiro@med.uni-goettingen.de (T.F. Outeiro), markus.zweckstetter@dzne.de (M. Zweckstetter).

Available online on ScienceDirect (www.sciencedirect.com).

1 These authors contributed equally.
}

of evidence suggested that the toxic species of $\alpha$ S are pre-fibrillar misfolded forms rather than insoluble neuronal deposits as found in Lewy bodies (Caughey and Lansbury, 2003; Cookson, 2009; Karpinar et al., 2009; Lashuel et al., 2002; Winner et al., 2011). One prevalent hypothesis attributes the toxicity of $\alpha$ S oligomers to their high membrane affinity, which might cause membrane distortion and membrane leakage (Auluck, 2010; Bodner et al., 2009; Butterfield and Lashuel, 2010; Karpinar et al., 2009).

Monomeric $\alpha \mathrm{S}$ is intrinsically disordered and comprises 140 amino acids that distribute in three distinct domains: a basic $\mathrm{N}$-terminal region (residues 1-60), a hydrophobic central domain (residues 61-95) and the acidic C-terminus (residues 96-140) (Polymeropoulos et al., 1997). Intra- and intermolecular contacts can be detected in monomeric, unfolded $\alpha S$ and are implicated in modulating the aggregation propensity (Bertoncini et al., 2005; Dedmon et al., 2005; Outeiro et al., 2008; Wu and Baum, 2010). The negatively charged C-terminus 
remains disordered in several conformational states such as monomeric, fibrillar and membrane-bound $\alpha \mathrm{S}$ (Del Mar et al., 2005; Eliezer et al., 2001; Qin et al., 2007; Ulmer et al., 2005; Vilar et al., 2008). In Lewy õbodies, $90 \%$ of $\alpha \mathrm{S}$ is estimated to be phosphorylated at $\mathrm{S} 129$ in the C-terminus (Fujiwara et al., 2002). However, the functional role of this phosphorylation is largely unknown (Oueslati et al., 2010; Sato et al., 2013). The C-terminus is also important in regulating $\alpha$ S aggregation through different modifications, such as ligand-binding (Fernandez et al., 2004; Goers et al., 2003) and truncation (Hoyer et al., 2004; Kim et al., 2002; Levitan et al., 2011).

The precise function of $\alpha \mathrm{S}$ remains equivocal (Marques and Outeiro, 2012), but several lines of evidence suggest that $\alpha S$ is involved in vesicle trafficking (Auluck, 2010; Lashuel et al., 2013; Waxman and Giasson, 2009). $\alpha$ S was reported to assist synaptic vesicle recycling, neurotransmitter release (Ben Gedalya et al., 2009; Liu et al., 2004) and the function of SNAREs (Chandra et al., 2005). Moreover, $\alpha$ S was suggested to have a role in the maintenance of synaptic vesicle pools (Murphy et al., 2000; Cabin et al., 2002), activity-dependent dopamine release (Abeliovich et al., 2000) and to act as a negative regulator of vesicle priming (Larsen et al., 2006). In line with a role in vesicle trafficking, altering the expression levels and biophysical properties of $\alpha \mathrm{S}$ and its familial mutants leads to deficits in vesicle trafficking at multiple stages in PD model systems (Auluck, 2010).

Rab GTPases are small guanine nucleotide binding proteins that play a key role in coordinating vesicle trafficking (Stenmark, 2009), and have been associated with $\alpha$ S-related neuronal dysfunction (Chen et al., 2013; Chung et al., 2009; Dalfo et al., 2004a,b; Kuwahara et al., 2008; Liu et al., 2009; Sancenon et al., 2012; Soper et al., 2011). In cellular and animal models of PD, $\alpha$ S overexpression disrupts vesicle trafficking between the endoplasmic reticulum (ER) and Golgi and overexpression of Rab1 attenuated $\alpha$ S toxicity (Cooper et al., 2006). Furthermore, Rab homeostasis is generally disturbed by $\alpha \mathrm{S}$ in yeast with overexpression of Rab8a, Rab1 and Rab3a being partially protective against $\alpha \mathrm{S}$ induced toxicity (Gitler et al., 2008). In particular, Rab8a - the Rab GTPase that is responsible for modulating post-Golgi vesicle trafficking - increased the number of $\alpha \mathrm{S}$-overexpressing Caenorhabditis elegans with wild-type neurons from $15 \%$ to $40 \%$, the strongest rescue effect found so far in this PD model (Gitler et al., 2008).

\section{Experimental section}

\section{Sample expression and purification}

Unlabeled and ${ }^{15} \mathrm{~N}$-labeled $\alpha \mathrm{S}$ was expressed and purified as described previously (Hoyer et al., 2002). Samples used for NMR spectroscopy contained ${ }^{15} \mathrm{~N}$-labeled $\alpha \mathrm{S}$ in $50 \mathrm{mM}$ HEPES buffer, $100 \mathrm{mM} \mathrm{NaCl}$ at pH 7.4. $\alpha$ S was phosphorylated at S129 by polo-like kinase 3 (PLK3) at $30{ }^{\circ} \mathrm{C}$ and reached full phosphorylation after $2 \mathrm{~h}$ in agreement with previous studies (Mbefo et al., 2010). Phosphorylated $\alpha \mathrm{S}$ (pS129- $\alpha \mathrm{S}$ ) was purified by semipreparative reverse-phase HPLC. Sample purity was tested by mass spectrometry. The C-terminal peptide of $\alpha S$ (113-140) with phosphorylation at $S^{129}$ was synthesized using standard solid-phase fluorenylmethoxycarbonyl chemistry. The peptide was purified by semipreparative reverse-phase HPLC, and the purity ( $>95 \%$ ) was analyzed by MS.

The human Rab8a gene was synthesized as codon-optimized DNA for the expression in Escherichia coli (MR GENE, Regensburg, Germany). Full length Rab8a was subcloned into a modified pET19 vector that contained an N-terminal hexa-histidine tag and a Tobacco Etch Virus (TEV) protease cleavage sequence. To label Rab8 with ${ }^{15} \mathrm{~N}$ and ${ }^{13} \mathrm{C}$ isotopes, the Rab8a construct was co-expressed with a plasmid encoding for GroES/ES chaperones (described previously in Bleimling et al., 2009) in E. coli BL21 (DE3) in minimal medium containing $1 \mathrm{~g} / \mathrm{L}$ ${ }^{15} \mathrm{NH}_{4} \mathrm{Cl}$ and $1 \mathrm{~g} / \mathrm{L}{ }^{13} \mathrm{C}$-D-glucose. The purification of Rab8a was performed as described previously (Bleimling et al., 2009). The preparation of GppNHp loaded Rab8a was performed as described (Hou et al., 2011).

\section{Co-immunoprecipitation of Rab8 and $\alpha S$}

Immunoprecipitation (IP) experiments were performed using lysates from rat hippocampus and mouse cortical synaptosomes (Choi et al., 2009). Dissected brain samples were homogenized in IP buffer (50 mM Tris-HCl pH 7.5; 0.5 mM EDTA; 150 mM NaCl; 0.05\% NP40) freshly supplemented with protease inhibitors (Roche Diagnostics, Mannheim, Germany). Lysates were pre-cleared by incubation with $20 \mu \mathrm{L}$ of protein $\mathrm{G}$ beads (Invitrogen, Barcelona, Spain) for $30 \mathrm{~min}$ at $4{ }^{\circ} \mathrm{C}$. The supernatants were incubated overnight at $4{ }^{\circ} \mathrm{C}$ with rotation either with anti-synuclein ( $10 \mu \mathrm{g} / \mathrm{mL}$; Santa Cruz Biotechnology, rabbit) or with anti-Rab8 antibody ( $10 \mu \mathrm{g} / \mathrm{mL}$; BD Bioscience, mouse). The immune complexes were then adsorbed for $3 \mathrm{~h}$ to protein $\mathrm{G}$ agarose beads at $4{ }^{\circ} \mathrm{C}$. Next, beads were washed according to the manufacturer's recommendation, resuspended in Laemmli buffer and heated at $100{ }^{\circ} \mathrm{C}$ for $5 \mathrm{~min}$. The resulted supernatants were resolved on a $12 \%$ SDSPAGE gel. After transferring proteins in nitrocellulose membranes, membranes were blocked and incubated overnight with the respective primary antibody, anti-synuclein (1:1000; Santa Cruz Biotechnology, rabbit) or anti-Rab8 (1:1000; BD Bioscience, mouse). Membranes were then incubated with secondary antibody (HRP-conjugated antimouse; GE Healthcare, Bucks, UK, 1:10,000). The immunoreactivity was visualized by chemiluminescence using an ECL detection system (Millipore, Billerica, MA, USA).

\section{NMR experiments}

NMR spectra were acquired at $15{ }^{\circ} \mathrm{C}$ on a Bruker Avance 600 NMR spectrometer using a triple-resonance cryoprobe equipped with $\mathrm{z}$-axis self-shielded gradient coils. Low temperature $\left(15^{\circ} \mathrm{C}\right)$ reduces aggregation of $\alpha S$ and the impact of amide proton exchange. $\alpha S$-Rab8a binding was followed using two-dimensional ${ }^{1} \mathrm{H}-{ }^{15} \mathrm{~N}$ HSQC experiments with 1024 and 512 complex points in the direct and indirect dimensions, respectively, 32 scans per increment and a recovery delay of $1.2 \mathrm{~s}$. Spectral widths were $8389 \mathrm{~Hz}$ and $1809 \mathrm{~Hz}$. Average ${ }^{1} \mathrm{H} /{ }^{15} \mathrm{~N}$ chemical shift perturbations were calculated according to $\left[\left(\Delta \sigma^{1} \mathrm{H}\right)^{2}+\left(\Delta \sigma^{15} \mathrm{~N}\right)^{2} / 25\right]$, where $\Delta \sigma^{1} \mathrm{H}$ and $\Delta \sigma^{15} \mathrm{~N}$ are the observed changes in ${ }^{1} \mathrm{H}$ and ${ }^{15} \mathrm{~N}$ chemical shifts.

For backbone resonance assignment of Rab8a, relaxation-optimized versions of 3D NMR experiments HNCA, HNCACB, and CBCA(CO)NH were recorded on ${ }^{13} \mathrm{C},{ }^{15} \mathrm{~N}$-labeled Rab8a at a Bruker Avance $800 \mathrm{NMR}$ spectrometer. In addition, 3D HNCO and $\mathrm{HN}(\mathrm{CA}) \mathrm{CO}$ experiments were recorded for the C-terminal truncated Rab8a variant, Rab8a- $\delta$ C. Based on the 3D spectra, assignment of $\mathrm{C} \alpha, \mathrm{C} \beta, \mathrm{N}$, and HN chemical shifts was obtained by an iterative procedure of automatic assignment using the program MARS (Jung and Zweckstetter, 2004a,b) and manual verification and extension of the assignment.

\section{$\alpha S$ fibrillization}

Aggregation of $\alpha \mathrm{S}$ was carried out in solutions of $60 \mu \mathrm{M}$ of $\alpha \mathrm{S}$ in $50 \mathrm{mM}$ HEPES, $100 \mathrm{mM} \mathrm{NaCl}, 0.01 \% \mathrm{NaN}_{3}$, pH 7.4. Larger species other than monomeric proteins were removed prior to aggregation using a $0.22 \mu \mathrm{m}$ membrane filter (Millipore, Billerica, MA, USA) followed by centrifugation at $60,000 \mathrm{rpm}$ for $2 \mathrm{~h}$ at $4{ }^{\circ} \mathrm{C}$ using a Beckman 17 ultracentrifuge equipped with TLA-100 rotor (Beckman Coulter, South Kraemer Boulevard Brea, CA, USA). A volume of $300 \mu \mathrm{L}$ of freshly prepared protein solution was incubated at $21{ }^{\circ} \mathrm{C}$ in glass vials under constant mixing with micro-stirring bars. Rab proteins were added prior to the start of aggregation at the specified molar ratio. At different time points, $5 \mu \mathrm{L}$ aliquots were taken from the aggregating sample and added into $2 \mathrm{~mL}$ of $5 \mu \mathrm{M}$ ThT in $50 \mathrm{mM}$ Na-glycine, pH 8.2. ThT fluorescence was measured on a Varian Cary Eclipse spectrofluorimeter using $3.5 \mathrm{~mL}$ quartz cuvettes (Hellma, Jena, Germany) with an excitation wavelength of $446 \mathrm{~nm}$ and emission at $480 \mathrm{~nm}$. Error bars were calculated from three independent aggregation assays. 


\section{Transmission electron microscopy}

For negative staining, a protein-containing solution was applied to glow-discharged carbon coated grids and stained with $1 \%$ uranyl acetate. Images were taken with a Philips CM120 electron microscope (Philips Inc.) at a defocus of $2.3 \mu \mathrm{m}$ using a TemCam 224A slow scan CCD camera (TVIPS, Gauting, Germany).

\section{Cell culture and transfection}

Neuroglioma $\mathrm{H} 4$ cells were maintained at $37{ }^{\circ} \mathrm{C}$ and $5 \% \mathrm{CO}_{2}$ in Optimum medium (Gibco) supplemented with 10\% Fetal Calf Serum and 1\% penicillin-streptomycin. Cells were seeded, one day prior to transfection in either 24-well plate, for western blot and cytotoxicity assay, or $\mu$-Dish $35 \mathrm{~mm}$ Ibidi dishes for immunocytochemistry. Triple transient transfections of $\alpha S$, synphilin-1 and either Rab8a or GFP were performed with Fugene 6 (Promega) according to the manufacturer's instructions.

\section{Site-directed mutagenesis}

SynT S129D and SynT S129A were generated by site directed mutagenesis (QuickChange II Site-Directed Mutagenesis Kit, Agilent Technologies) using SynT as a template. The selected primers for S129D were: "GGC TTA TGA AAT GCC TGA TGA GGA AGG GTA TCA AG" and "CTT GAT ACC CTT CCT CAT CAG GCA TTT CAT AAG CC" while for S129A the primers were "CTT ATG AAA TGC CTG CTG AGG AAG GGT ATC" and "CTT ATG AAA TGC CTG CTG AGG AAG GGT ATC" forward and reverse respectively.

\section{Immunocytochemistry}

For immunofluorescence microscopy cells were fixed with $4 \%$ paraformaldehyde (PFA) $48 \mathrm{~h}$ after transfection, sequentially treated with $0.5 \%$ Triton X-100 and 1.5\% normal goat serum in PBS. Cells were incubated with anti- $\alpha$ S antibody (BD 610787, 1:1000) at $4{ }^{\circ} \mathrm{C}$ overnight, followed by incubation with Alexa Fluor donkey anti-mouse 555 (Invitrogen A31570, 1:1000) secondary antibody. Before visualization, cells were stained with Hoechst (Molecular Probes 33258). Images were captured, in a blind process, using a Leica DMI 6000B microscope (Leica, Wetzlar, Germany) and analyzed with ImageJ software (NHI, USA). For counting the number of aggregates per cell, three different categories were chosen: cells with no aggregates, cells with less than 10 aggregates and cells with 10 or more aggregates.

NIAD-4 staining (Glixx Labs, USA), to identify the presence of amyloid-like structures, was performed by incubating cells with the dye at a final concentration of $10 \mu \mathrm{M}$ for $30 \mathrm{~min}$ at room temperature followed by immunocytochemistry as previously described.

\section{Cytotoxicity assay}

Cytotoxicity was measured via release of LDH into the culture medium with the Cytotoxicity Detection Kit (LDH) (Roche, Mannheim, Germany). Basic LDH release was measured in non-transfected cells, and the maximal LDH release was measured by cell lysis in $2 \%$ Triton $\mathrm{X}-100$. Absorbance was measured with the Infinite M2000 PRO (Tecan, Mainz, Germany) plate reader at $490 \mathrm{~nm}$. Experimental values were calculated in percentages of the maximal LDH release and normalized to empty vector ( $\mathrm{pSI})$.

\section{Immunoblotting analysis}

Cell lysates were electrophoresed through 15\% polyacrylamide gels, then transferred to nitrocellulose membranes (GE Healthcare) and blocked with $5 \%$ skim milk. Membranes were then incubated with primary antibodies (anti- $\alpha$ S, BD, 1:4000; anti-Rab8a, BD, 1:4000 or anti- $\beta$-actin, Sigma-Aldrich, A-5441, 1:10,000) overnight at $4{ }^{\circ} \mathrm{C}$. HRPconjugated secondary antibodies (GE Healthcare, NXA 931, 1:10,000) were applied for $1 \mathrm{~h}$ at room temperature and visualized on Alpha Imager (Alpha Innotech).

\section{Fly stocks}

Flies were maintained on standard maize food at $25{ }^{\circ} \mathrm{C}$ in LD 12:12. The $w$; +; ple-GAL4 (8848), w; UASRab8-YFP; +(9782), w; +; UAS $\alpha S_{w t}$ and $w$; UASeGFP; $+(5431)$ lines were obtained from the Bloomington Stock Center (Indiana). The c164-GAL4 driver was kindly donated by Juan Botas (Baylor College of Medicine). The UASlacZ, UAS $\alpha S_{w t}$ and $U A S \alpha S_{T P S}$ were a gift from Alf Herzig (Max-Planck-Institut für Biophysikalische Chemie).

\section{Larval crawling assay}

Briefly, crosses were set up in standard maize fly food mixed with 0.05\% Bromophenol Blue (FisherBiotech) as described previously (Steinert et al., 2012). Young deep blue colored third instar wandering larvae were used for the crawling assay. Each larva was washed in distilled water and placed in the middle of a $145 \mathrm{~mm}$ Petri dish coated with $0.8 \%$ agarose. The distance covered by the larva in 2 min was manually tracked on a transparent sheet placed on top of the Petri dish lid. The tracks were scanned and the distance was calculated using Image J software (http://rsbweb.nih.gov/ij/).

\section{Negative geotaxis assay}

Negative geotaxis was determined in flies as previously described (Ali et al., 2011). Ten days old flies were placed in a cylinder consisting of two empty fly vials taped together at their open ends. An $8 \mathrm{~cm}$ line was drawn from one end defining the threshold that flies must reach in order to be scored. Prior to initiating trials, flies were acclimatized to the apparatus for $1 \mathrm{~min}$, and then the tube was tapped gently in order to gather the flies at the bottom of the tube. The flies were permitted to fly or scale the sides of the tube for $10 \mathrm{~s}$ and the number of flies passing the threshold recorded. The experiment was repeated 10 times, with a one minute rest in between trials.

\section{Detection of dopaminergic neurons in Drosophila by immunocytochemistry}

Adult flies aged 30 days post-eclosion were collected and fixed overnight at $4{ }^{\circ} \mathrm{C}$ in $4 \%$ formaldehyde-PBS containing $0.5 \%$ of Triton X-100. Brains were dissected in ice-cold PBS and further permeabilised with $3 \times 20$ min washes with PBST (with $1 \%$ Triton X-100). Brains were then blocked with $10 \%$ goat serum in PBST for at least $1 \mathrm{~h}$ and incubated overnight at $4{ }^{\circ} \mathrm{C}$ with mouse anti-TH antibody (1:100, ImmunoStar). Before and after the secondary antibody incubation (anti-mouse Cy5, 1:500, Abcam), brains were washed for 20 min with PBST. A solution of 3\% N-propylgallate and 80\% glycerol in PBS was used for mounting the samples which were then visualized and analyzed on an Olympus FV1000 confocal microscope and processed with Olympus software, respectively.

\section{Results}

\section{$\alpha$ S interacts with Rab8a in rodent brain}

To determine whether $\alpha$ S and Rab8a interact at endogenous levels in the brain, we performed co-immunoprecipitation assays. Immunoprecipitation (IP) of $\alpha$ S pulled down Rab8a both in rat hippocampus and mouse cortical synaptosomes (Fig. 1A) while no signal was observed in the control IP with rabbit serum, demonstrating the specificity of the IP (Supplementary Fig. S1). Furthermore, in mouse cortical synaptosome preparations, immunoprecipitation of Rab8a successfully pulled 
A

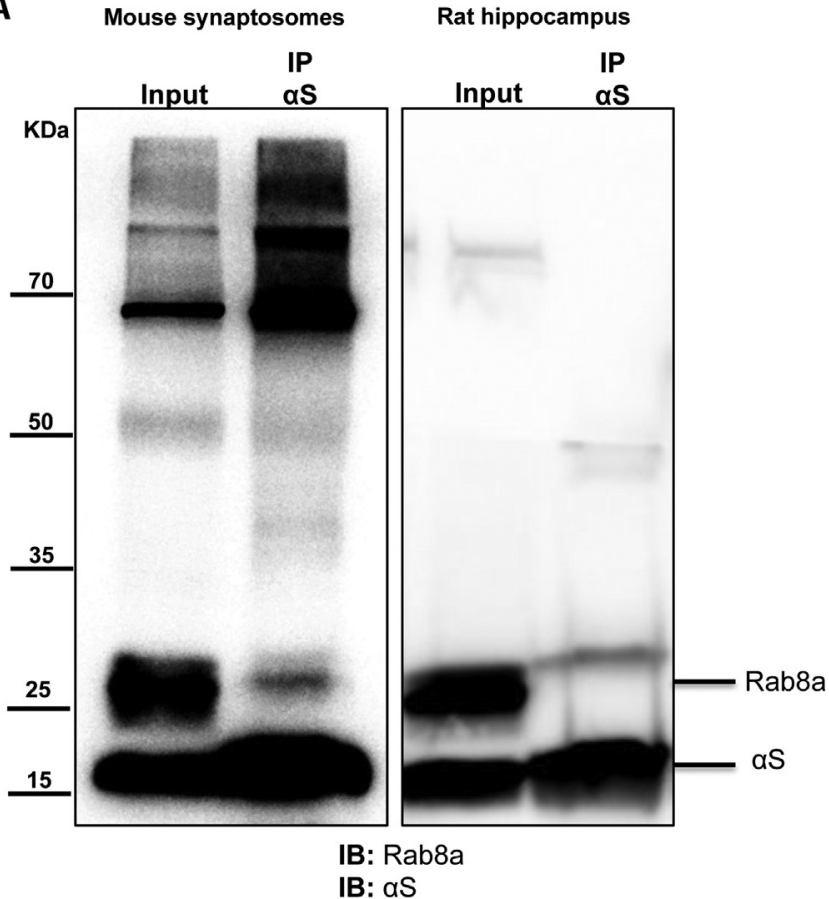

B

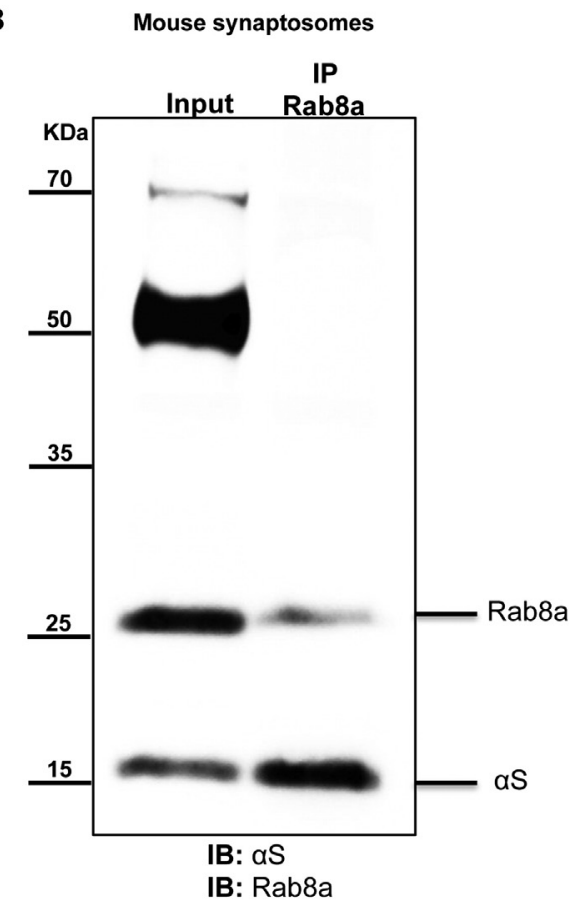

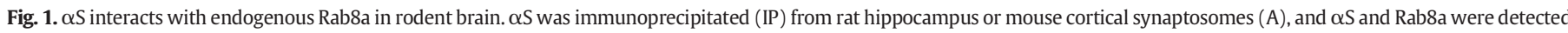

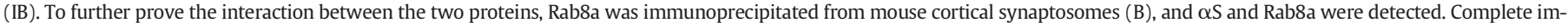
munoblots are shown to demonstrate the specificity of the interaction.

down $\alpha$ S (Fig. 1B). Thus, we concluded that $\alpha$ S and Rab8a interact under physiological conditions and the interaction occurs also in the synaptic compartment.

\section{The C-terminus of $\alpha$ S binds to the switch 1 and 2 regions of Rab8a}

To obtain molecular insight into the binding of Rab8a to $\alpha \mathrm{S}$, we employed nuclear magnetic resonance (NMR) spectroscopy. NMR resonances are highly sensitive probes of protein-protein and protein-ligand interactions and therefore allow a detailed description of interaction interfaces and binding affinities (Craik and Wilce, 1997). $\alpha S$ and Rab8a were produced recombinantly and changes in chemical shifts and signal intensities were followed in two-dimensional ${ }^{1} \mathrm{H}-{ }^{15} \mathrm{~N}$ correlation spectra (heteronuclear single quantum coherence, HSQC) of $\alpha$ S. Significant changes in NMR signals were observed for residues G111 to A140 of $\alpha \mathrm{S}$ (Fig. 2A). In both the GDP- and GppNHp(a hydrolysis-resistant structural analog of GTP) bound states, Rab8a selectively interacted with the acidic C-terminus of $\alpha \mathrm{S}$ (Figs. 2A, B). Dissociation constants, $K_{d}$, for the interaction were determined from the concentration-dependent chemical shift changes of the strongly affected and well-resolved $\alpha$ S resonances of A124, Y125, E126, M127, D134 and E137: $K_{d}$ values for Rab8a(GDP) and Rab8a(GppNHp) binding to $\alpha$ S were $0.19 \pm 0.01 \mathrm{mM}$ and $0.45 \pm 0.05 \mathrm{mM}$, respectively. Thus, the GDP-bound state of Rab8a binds slightly stronger to $\alpha \mathrm{S}$ than the GppNHp-bound form.

To identify the binding site of $\alpha S$ on Rab8a, we determined the sequence-specific backbone resonance assignment of Rab8a(GDP). In the ${ }^{15} \mathrm{~N}-{ }^{1} \mathrm{H}$ HSQC of Rab8a, 175 backbone signals for 207 non-proline residues were observed (Fig. $3 \mathrm{~A}$ ). The remaining residues are probably not detectable due to conformational flexibility, in line with the known dynamic nature of the switch 1 and switch 2 regions of Rab proteins in the GDP-bound state (Itzen and Goody, 2011). 161 out of these signals could be assigned unambiguously. Based on the resonance assignment, the titration of Rab8a(GDP) with $\alpha$ S revealed that residues in the G2 loop, as well as the observable residues of the $\alpha 2$ helix of Rab8a exhibited strong changes in NMR signal position as a result of $\alpha \mathrm{S}$ binding (Fig. 3B). In addition, these residues showed increased signal intensities, indicating changes in backbone dynamics in the switch $1 / 2$ region upon $\alpha \mathrm{S}$ binding (Figs. 3C, D). Notably, the switch 1 (G2 loop) of Rab8a has previously been suggested to be highly dynamic and to
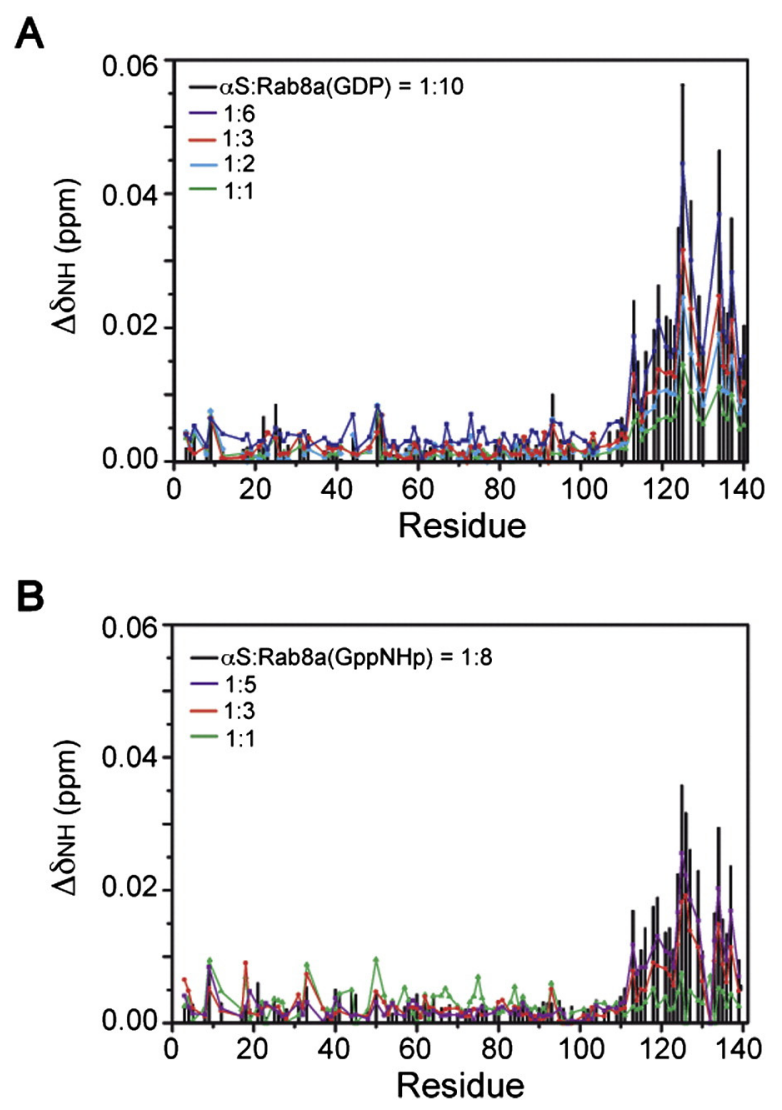

Fig. 2. Rab8a binds to the $\mathrm{C}$-terminus of $\alpha \mathrm{S}$. Averaged NMR chemical shift perturbation of ${ }^{1} \mathrm{H} /{ }^{15} \mathrm{~N}$ resonances of $\alpha \mathrm{S}$ in the presence of Rab8a(GDP) (A) and Rab8a(GppNHp) for molar ratios up to $1: 10$ and $1: 8$ respectively of $\alpha$ S/Rab8a (B). 
A
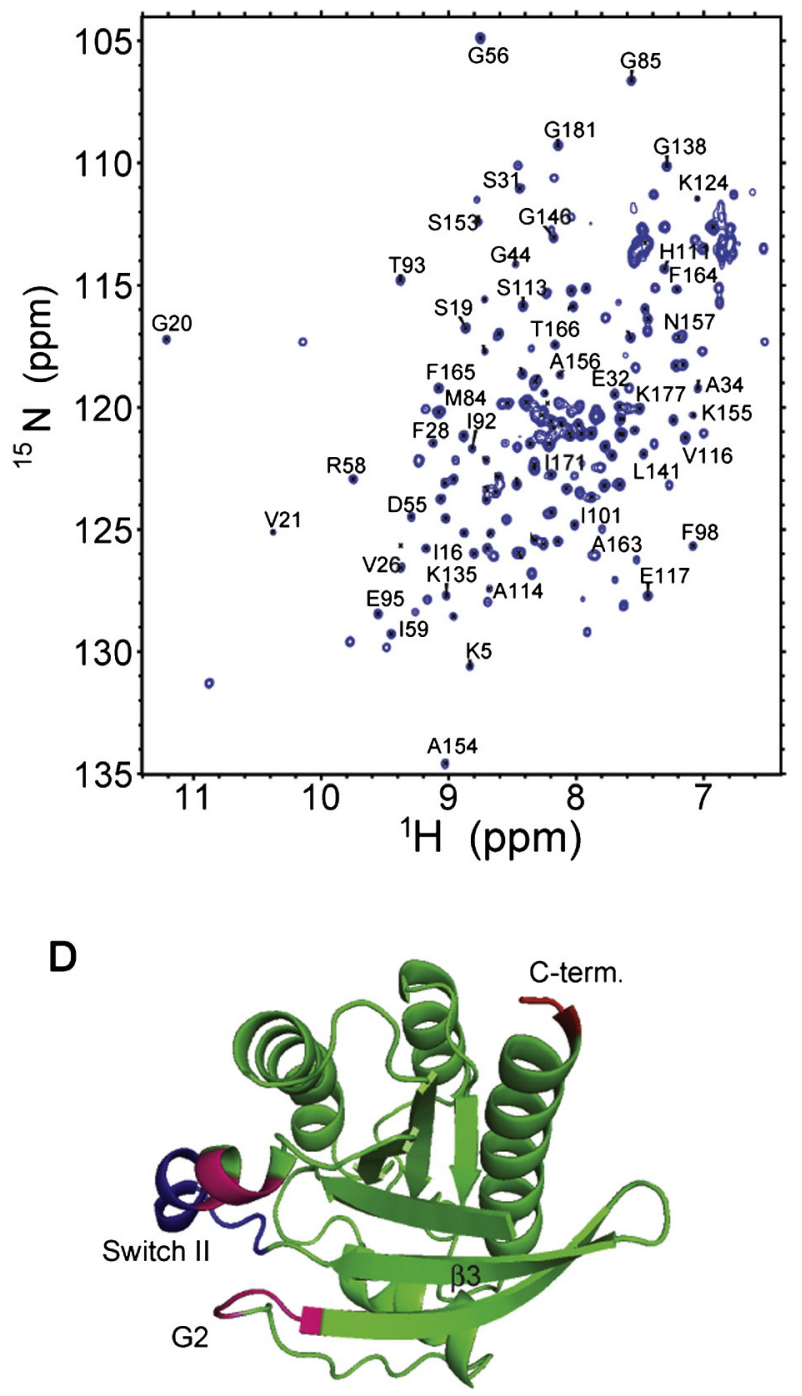

B
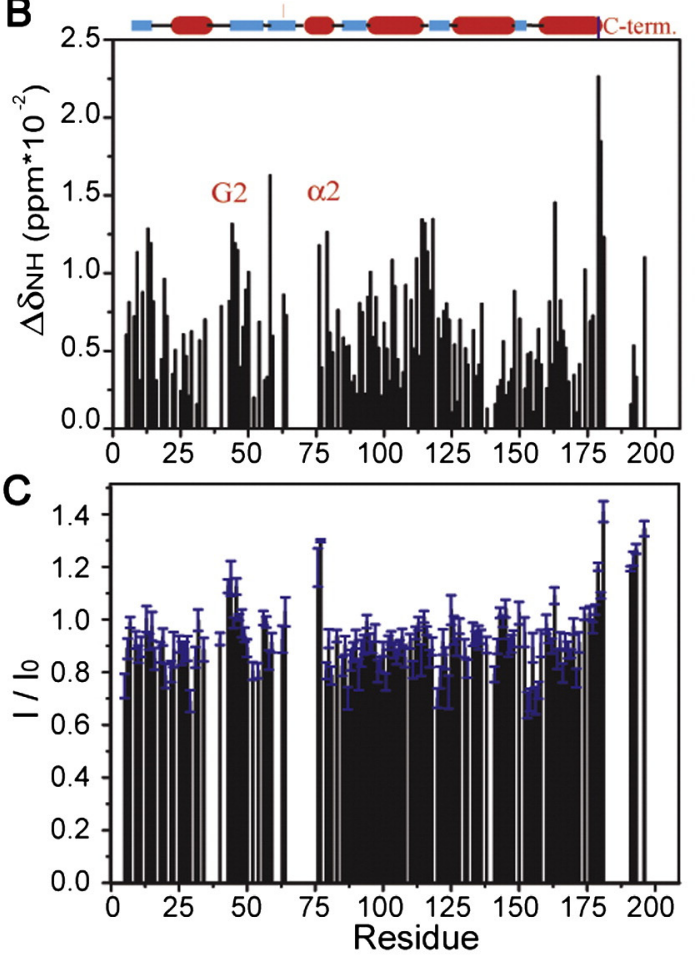

E

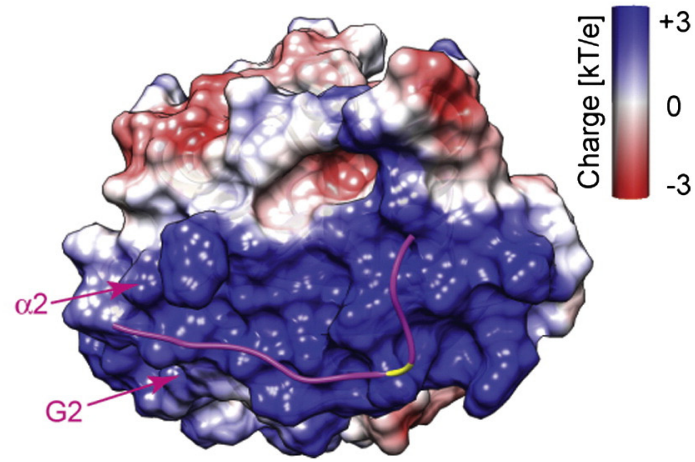

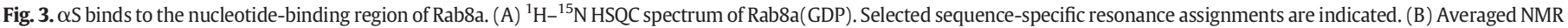

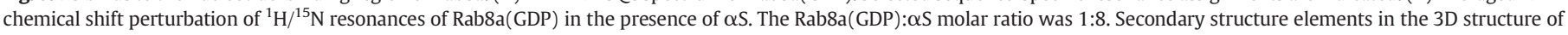

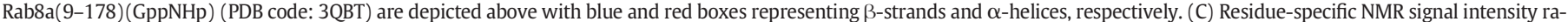

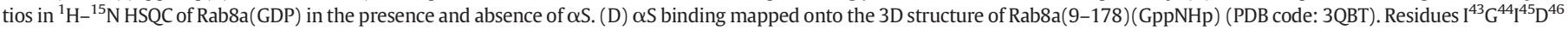

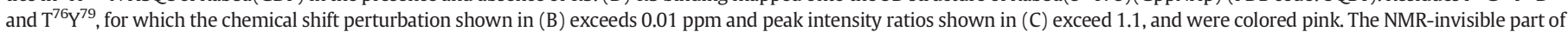

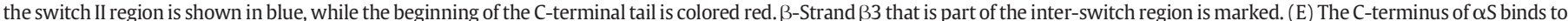

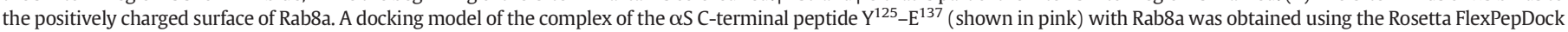

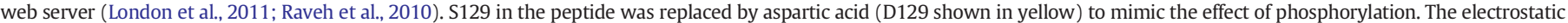
potential was calculated using the program APBS (Baker et al., 2001) on the basis of the 3D structure of Rab8a(9-178)(GppNHp) (PDB code: 3QBT).

experience large conformational changes between different nucleotide states (Itzen and Goody, 2011). Inspection of the 3D structure of Rab8a showed that the G2 loop is part of a positively charged surface patch (Fig. 3E). Besides changes in the switch $1 / 2$ region, NMR resonances of residues A173-G181 and I193-T194 at the positively charged C-terminus of Rab8a were perturbed upon the addition of $\alpha \mathrm{S}$ (Figs. 3B, C). Thus, the C-terminus of Rab8a might provide a second independent binding site, as very similar chemical shift changes were observed in the switch $1 / 2$ region when using a Rab8a variant, Rab8a- $\delta C$, truncated at position 178 (Supplementary Fig. S2).

\section{Phosphorylation at S129 tightens the $\alpha$ S-Rab8a interaction}

Phosphorylation at S129 (pS129) (Fig. 4A) is the most abundant post-translational modification of $\alpha \mathrm{S}$ in PD (Anderson et al., 2006;

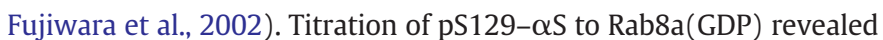
that, at the same molar ratio, Rab8a caused stronger NMR signal attenuation in $\mathrm{pS} 129-\alpha \mathrm{S}$ than in wild-type $\alpha \mathrm{S}$ (Figs. 4B, C). In particular, the resonance of phosphorylated S129 completely disappeared (Fig. 4B), indicating that it is strongly involved in the interaction. In line with a phosphorylation-dependent regulation of the $\alpha \mathrm{S}$-Rab8a interaction, the S129D variant of $\alpha S$, which is widely used to mimic phosphorylation in vivo (Sato et al., 2013), results in signal attenuation stronger than the wild-type protein (Fig. 4C). Taken together, the NMR data demonstrate that phosphorylation of $\alpha \mathrm{S}$ at S129 promotes binding of $\alpha \mathrm{S}$ to Rab8a.

\section{Rab8a enhances $\alpha$ S fibrillization}

Aggregation of $\alpha \mathrm{S}$ has been tightly linked to neurotoxicity in PD (Lashuel et al., 2013). Following identification of the Rab8a/ $\alpha S$ 
A $\alpha S: L^{100}$ GKNEEGAPQE ${ }^{10}$ GILEDMPVDP $^{120}$ DNEAYEMPSE ${ }^{130}$ EGYDYEPEA $^{140}$

B

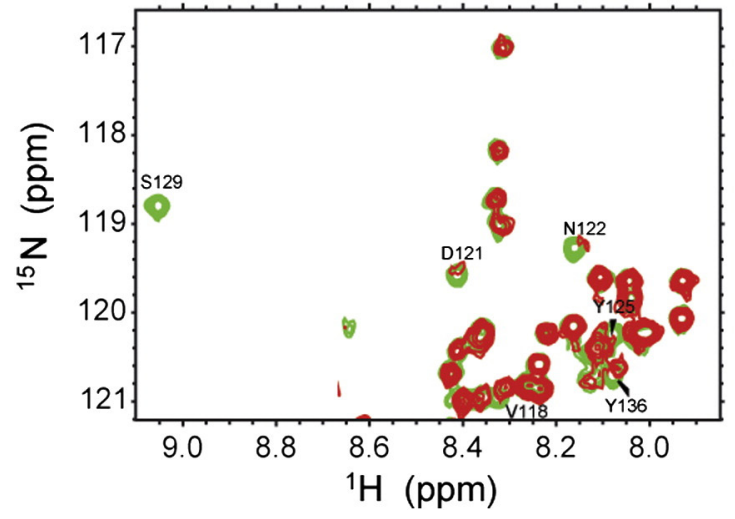

C

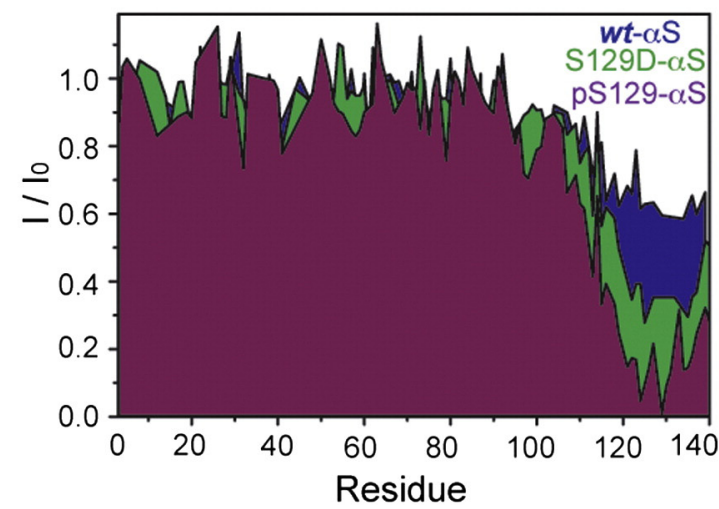

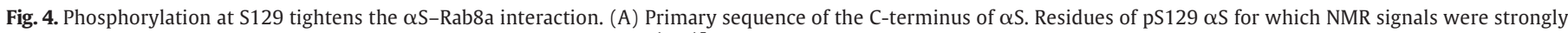

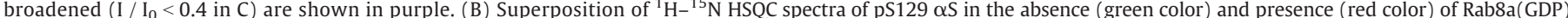

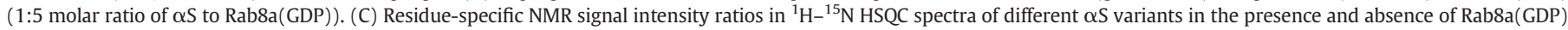
$(\alpha S: R a b 8 a(G D P)$ molar ratio of 1:5). Data for wild-type, S129D and pS129 $\alpha$ S are shown in blue, green and red, respectively.

interaction, we investigated the role of Rab8a in modulating $\alpha \mathrm{S}$ aggregation in vitro and in cells. First, $\alpha \mathrm{S}$ was incubated in vitro with fulllength Rab8a(GDP) under aggregation-promoting conditions and fibrillization kinetics were monitored using the amyloid-specific dye Thioflavin T (ThT). Rab8a(GDP) enhanced fibrillization of $\alpha$ S at different Rab8a(GDP): $\alpha$ S molar ratios (Fig. 5A). Already at a Rab8a(GDP): $\alpha S$ molar ratio of 0.5:1 the lag phase of fibrillization was reduced from $24 \mathrm{~h}$ to $15 \mathrm{~h}$. Even more dramatic, however, was the increase in the rate of $\alpha$ S fibril elongation at equimolar ratio (Fig. 5A). Incubation of Rab8a alone did not result in enhanced ThT activity (Supplementary Fig. S3), excluding a significant contribution of Rab8a aggregation to the ThT signal.
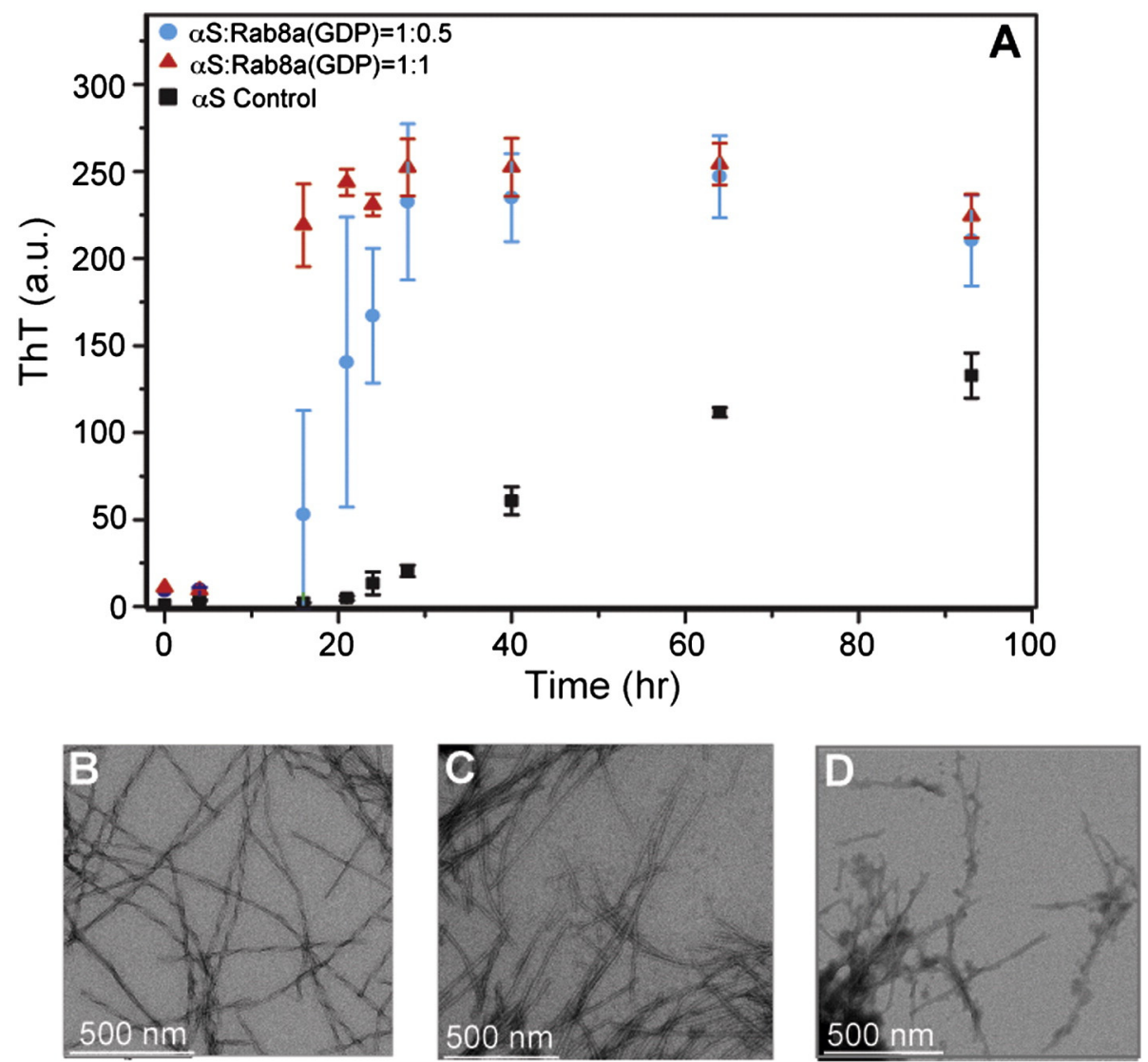

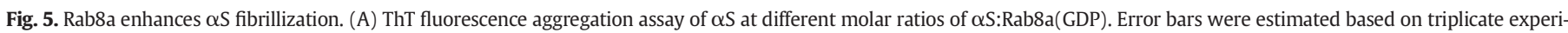
ments. (B-D) Electron micrographs of samples taken after $90 \mathrm{~h}$ of aggregation as shown in (A). Images for the $\alpha \mathrm{S}$ control (B), and at molar ratios of 1:0.5 (C) and 1:1 (D). 
Electron microscopy (EM) was used to morphologically assess the fibrillar species formed by $\alpha S$ in the absence and presence of Rab8 (GDP) (Figs. 5B-D). Compared to fibrils of $\alpha \mathrm{S}$ alone, $\alpha \mathrm{S}$ fibrils in the presence of Rab8a were shorter and had a tendency to stick together. In addition, with increasing amounts of Rab8a roundish clumps were visible on the fibrillar surface, suggesting that Rab8a might bind to $\alpha S$ fibrils. An interaction of Rab8a with the C-terminus of fibrillar $\alpha \mathrm{S}$ appears possible, as a variety of investigations have shown that the C-terminus of $\alpha \mathrm{S}$ remains disordered and accessible in $\alpha$ S fibrils (Del Mar et al., 2005; Vilar et al., 2008).

\section{Rab8a enhances cellular $\alpha S$ aggregation and reduces $\alpha$ S-induced toxicity}

To obtain further insight into the effect of Rab8a on $\alpha \mathrm{S}$ aggregation and $\alpha$ S-induced toxicity, we used a previously described cell model (Fig. 6A) (McLean et al., 2001) that accumulates amyloid-like $\alpha$ S structures, as demonstrated by staining with NIAD-4, an amyloid-binding dye (Fig. 6D) (Olzscha et al., 2011). We observed that endogenous and overexpressed Rab8a co-localized with $\alpha$ S-positive inclusions (Supplementary Fig. S4). In addition, overexpression of Rab8a resulted in a 30\% increase in the number of cells with inclusions (Fig. 6B), in line with Rab8a-promoted fibrillization of $\alpha S$ in vitro (Fig. 5). Strikingly, the S129D mutant of $\alpha$ S, which carries a negative charge in position 129 to mimic phosphorylation and which binds more strongly to Rab8a (Fig. 4), further increased the number of inclusions per cell in the presence of Rab8a (Fig. 6C). On the other hand, the S129A mutant that blocks phosphorylation, showed an increase in the percentage of cells with no aggregates (Fig. 6C). Taken together the data suggest both a role for Rab8a and $\alpha \mathrm{S}$ phosphorylation in the process of $\alpha \mathrm{S}$ aggregation in a cellular context.

Next, we investigated whether Rab8a also influenced toxicity in the same cell model that was used for analysis of $\alpha \mathrm{S}$ aggregation. Toxicity was determined $48 \mathrm{~h}$ after transfection by release of lactate dehydrogenase (LDH) into the medium. Our experiments showed that overexpression of Rab8a increased toxicity only moderately relative to control transfections, while $\alpha \mathrm{S}$ overexpression resulted in a more than twofold increase in toxicity (Fig. 7A). However, when Rab8a and $\alpha S$ were coexpressed, cellular toxicity decreased significantly when compared to $\alpha$ S alone (Fig. 7A). Notably, overall protein levels were not affected by coexpression of the proteins, ruling out the possibility that the observed protection was due to a reduction in the levels of $\alpha \mathrm{S}$ (Fig. 7B). In case of the S129D mutant of $\alpha$ S, cellular toxicity was further reduced when coexpressed with Rab8a (Fig. 7A). We also observed a reduction in toxicity with the S129A mutant, but this effect might also be related with the effect of the mutant on aggregation, since it leads to a reduction in the percentage of cells displaying inclusions (Fig. 7A and Fig. 6).

\section{Rab8 ameliorates $\alpha$ S-dependent behavioral defects in fruit flies}

We next investigated overexpression of Rab8 - the Drosophila melanogaster ortholog of Rab8a - in two robust fruit fly models of $\alpha \mathrm{S}$ toxicity. The first is a widely used model in which the transgene encoding $\alpha \mathrm{S}$ was inserted randomly into the genome using P-element based transgenesis (Feany and Bender, 2000), and the second is a more recent model we generated in which individual transgenes encoding wild-type or mutant versions of $\alpha \mathrm{S}$ were targeted into a specific genomic location using the $\varphi \mathrm{C} 31$-based site specific recombination system, reducing positional effects and eliminating insertional mutagenesis concerns (Karpinar et al., 2009). $\alpha$ S expression has been extensively studied in flies as a model of PD, and yields several diseaserelevant phenotypes, including formation of Lewy bodies, dopaminergic neuron loss, locomotor impairments, and abnormal circadian rhythmicity (Feany and Bender, 2000; Gajula Balija et al., 2011; Karpinar et al., 2009; Pienaar et al., 2010). Here, we took advantage of the GAL4/UAS bitransgenic system to drive the expression of $\alpha \mathrm{S}$ in moto- and dopaminergic neurons using c164 and ple drivers, respectively, and to study locomotor behavior of third instar larvae. The expression of $\alpha \mathrm{S}$ in these tissues caused a significant reduction in the distance crawled by the larvae compared to controls (Fig. 8). Coexpression of Rab8 with $\alpha \mathrm{S}$ in either motoneurons or dopaminergic neurons dramatically rescued this phenotype $(\mathrm{p}<0.01$ and $\mathrm{p}<0.001$, respectively, Figs. $8 \mathrm{~A}$ and $B)$. In order to exclude that the observed rescue was due to titration effects caused by the presence of multiple UAS transgenes, we also analyzed the crawling behavior in larvae co-expressing both eGFP and $\alpha$, and found no difference with the larvae expressing $\alpha \mathrm{S}$ alone, further supporting a protective role of Rab8.

We then validated Rab8 protection using our recently-developed $\varphi \mathrm{C} 31 \alpha \mathrm{S}$ lines. The lines tested carry a transgene expressing either wild-type $\alpha S$ or a pre-fibrillar mutant in which three alanines are substituted with proline residues (TP) (Gajula Balija et al., 2011). A significant decrease in larval crawling was observed when either WT or TP $\alpha \mathrm{S}$ was expressed in the motoneurons ( $p<0.001$, Fig. 8C) or dopaminergic neurons ( $p<0.001$, Fig. 8D). Overexpression of Rab8 was protective in flies expressing both $\alpha \mathrm{S}$ forms in either neuronal population tested (Figs. 8C, D).

To further explore locomotor activity we performed climbing assays in adult flies, which measure negative geotaxis (Ali et al., 2011). We found that ten day old flies pan-neuronally expressing $\alpha S$ via the elavGAL4 driver exhibit a significant $~ 55 \%$ reduction in climbing compared to controls ( $p<0.001$, Fig. 9). Strikingly, coexpression of Rab8 with $\alpha$ S strongly rescued this locomotor impairment $(p<0.001)$, supporting our observations in larvae, and indicating that Rab8 is able to reverse $\alpha \mathrm{S}$-dependent behavioral phenotypes in an animal model (Fig. 9).

Finally we investigated whether Rab8A could reverse the loss of dopaminergic neurons caused by the expression of $\alpha$ S. The adult Drosophila brain possesses several dopaminergic neuron clusters which are classified depending on their brain region localization (Nowicki and Oxenford, 1989). We focused our analyses on three clusters of neurons located on the posterior inferiormedial protocerebrum, the $\mathrm{PPL}_{1}, \mathrm{PPM}_{2}$ and $\mathrm{PPM}_{3}$ neurons. We found that the expression of $\alpha \mathrm{S}$ with either the elav or ple driver caused a significant reduction of neurons in the $\mathrm{PPL}_{1}$ cluster (Fig. 10, $\mathrm{p}<0.01$ ). We also observed a significant reduction of the $\mathrm{PPM}_{3}$ neurons $(\mathrm{p}<0.05)$, whereas the $\mathrm{PPM}_{2}$ group appeared to be only marginally affected by the expression of $\alpha \mathrm{S}$ (right and middle panels in Fig. 10, respectively). Strikingly, the co-expression of Rab8 with $\alpha \mathrm{S}$ fully rescued the loss of dopaminergic $\mathrm{PPL}_{1}$ neurons with either driver $(\mathrm{p}<0.05)$. In addition, the loss of $\mathrm{PPM}_{3}$ neurons was partially rescued by Rab8 co-expression with the elav driver $(\mathrm{p}<0.01)$.

\section{Discussion}

Increasing evidence suggests that defects in vesicular trafficking are important for the pathogenic events leading to PD (Auluck, 2010; Lashuel et al., 2013; Waxman and Giasson, 2009). Several Rab GTPases were suggested to interact aberrantly with $\alpha$ S in Dementia with Lewy bodies (Soper et al., 2008, 2011; Sung et al., 2001). In addition, Rab proteins colocalize with glial inclusions containing $\alpha \mathrm{S}$ in multiple system atrophy (Dalfo and Ferrer, 2005; Nakamura et al., 2000), Rab GTPases were found in vesicle clusters induced by $\alpha S$ overexpression in yeast (Gitler et al., 2008), and overexpression of the Rab GTPases Rab1, Rab3a and Rab8a decreased $\alpha$ S-induced neurotoxicity (Cooper et al., 2006; Gitler et al., 2008). The Rab GTPase Rab8a, which showed the strongest rescue of $\alpha \mathrm{S}$-toxicity in the nematode PD model (Gitler et al., 2008), is associated with recycling endosomes and basolateral trafficking events from the trans-Golgi network to the plasma membrane (Henry and Sheff, 2008). Also, Golgi fragmentation was recently shown to be Rab and SNARE dependent in cellular models of PD, further linking Rab8 with $\alpha$ S (Rendon et al., 2013). Although the genetic variant A30P $\alpha$ S has been observed to co-precipitate with Rab8 in transgenic mice (Dalfo et al., 2004b), no direct interaction between Rab8a, or any 
A
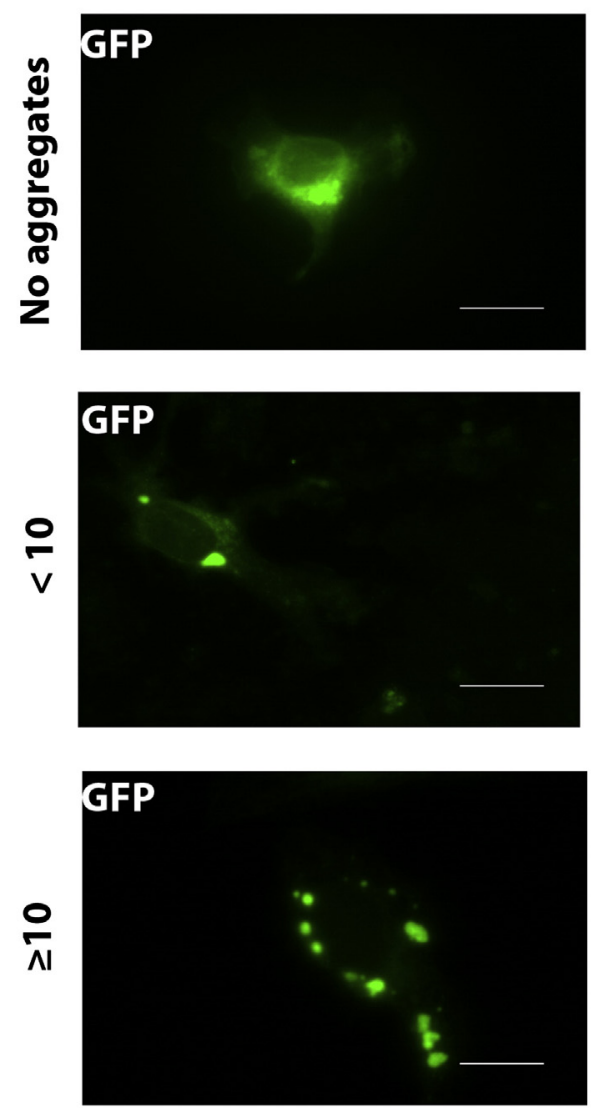

B

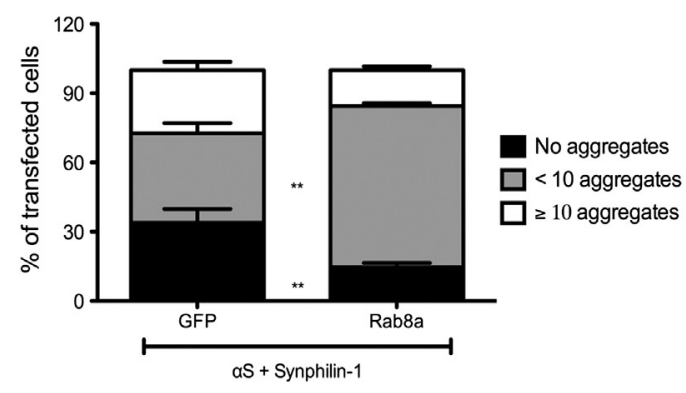

D

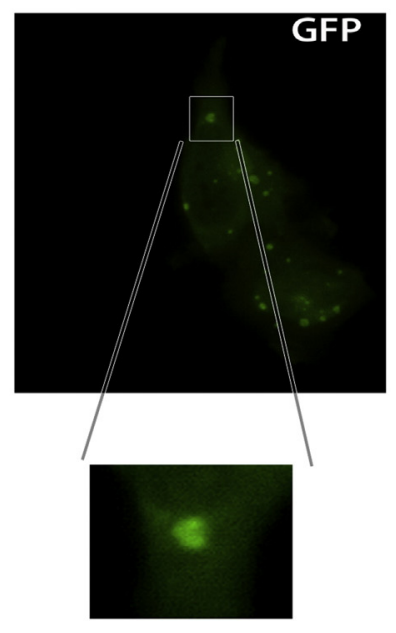

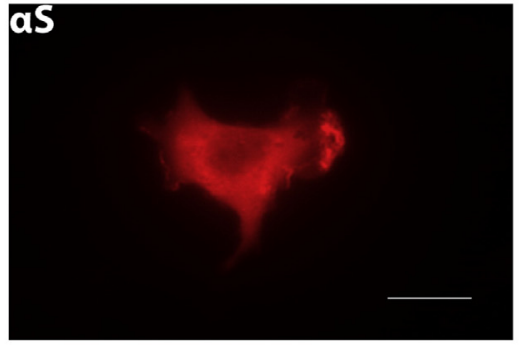
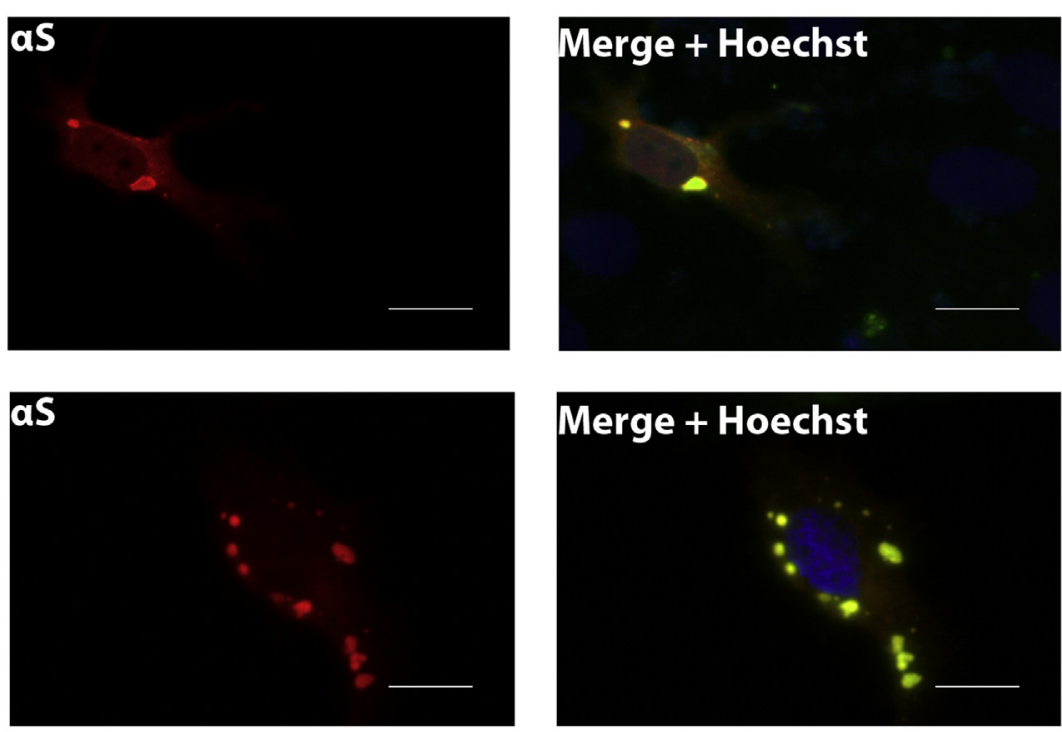

\section{Merge + Hoechst}

C
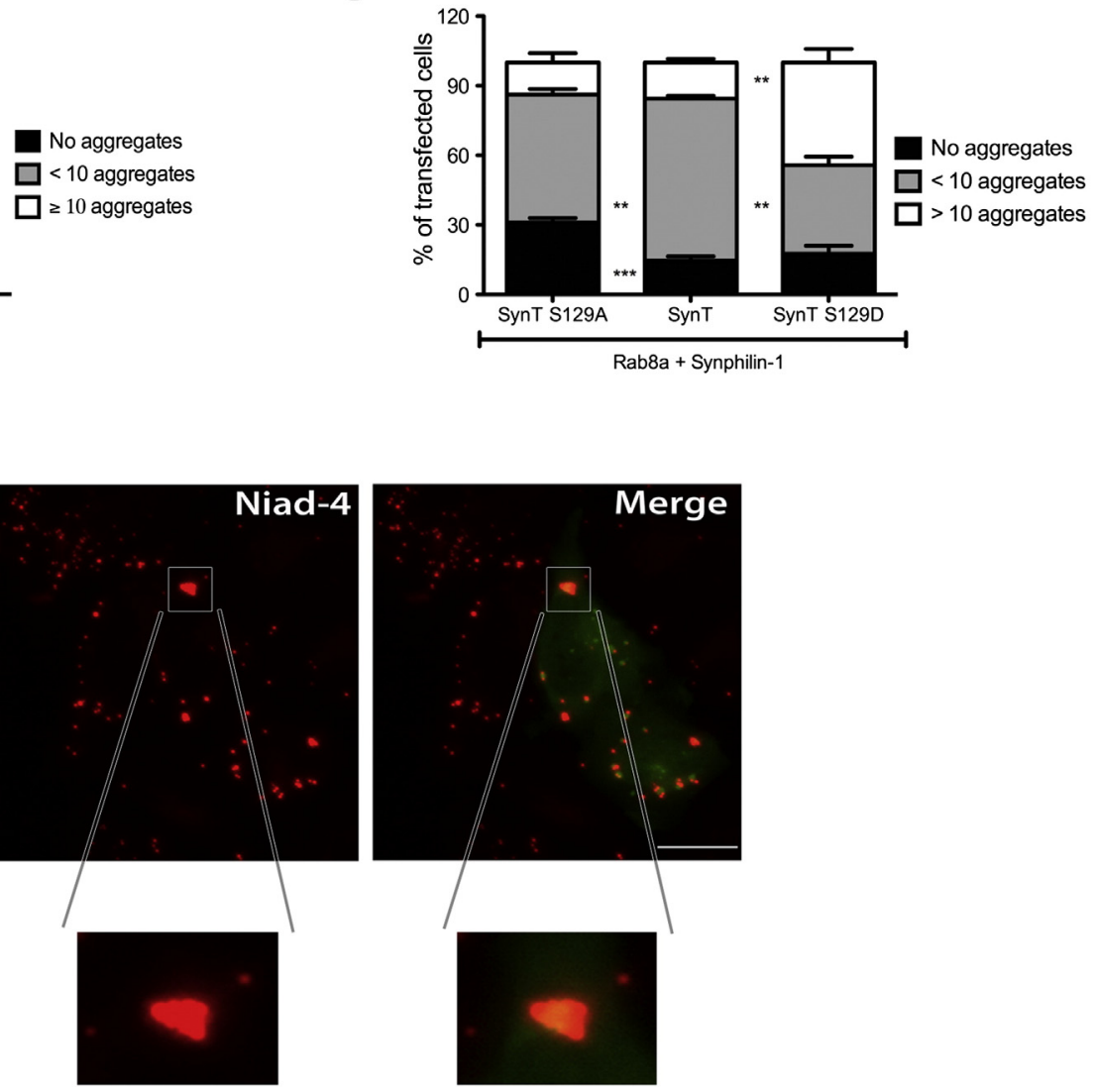

Merge + Hoechst
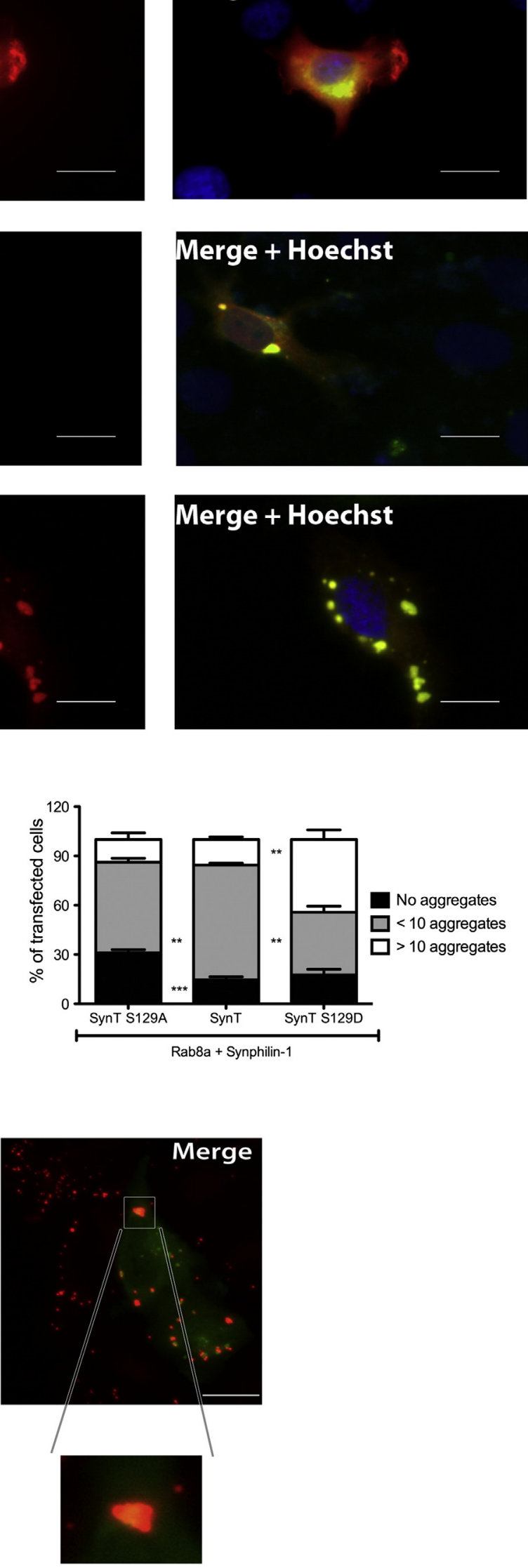
A

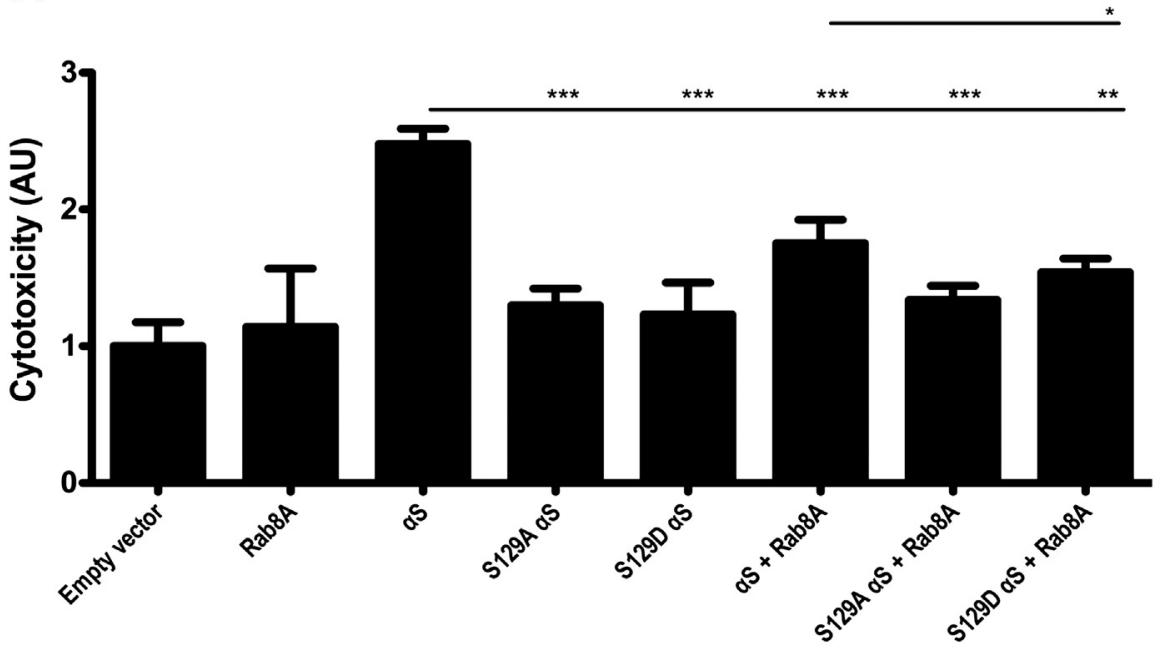

B

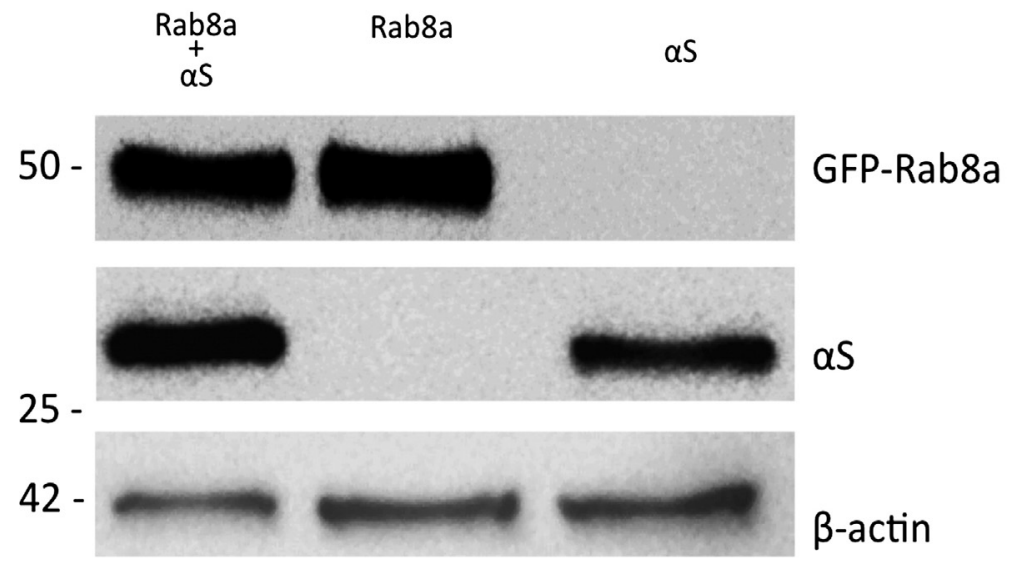

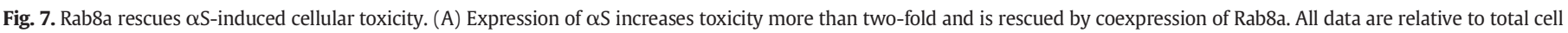

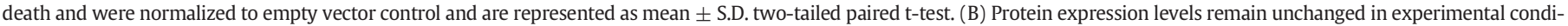
tions. $\beta$-Actin served as a loading control (immunoblots representative from 3 independent experiments are shown).

other Rab GTPase, with $\alpha$ S has been reported thus far. Here we demonstrated that $\alpha \mathrm{S}$ is associated with Rab8a in the rat hippocampus as well as mouse cortical synaptosomes (Fig. 1). NMR spectroscopy revealed the molecular details of the interaction and linked key sites of the two proteins - that is the C-terminus of $\alpha \mathrm{S}$ and the switch $1 / 2$ region of Rab8a (Figs. 2, 3). The pathological relevance of the interaction is supported by the observation that phosphorylation of S129 in $\alpha$ S enhances the binding (Fig. 4) and modulates the influence of Rab8a on $\alpha$ S aggregation and cellular toxicity (Figs. 6, 7). It remains to be seen if other Rab proteins can directly bind to $\alpha$ S in vitro and in vivo and whether their effect on $\alpha$ S-related neurotoxicity is mediated by a direct interaction.

The switch between the GDP- and GTP-bound states of Rab proteins is a fundamental process influencing a wide range of protein functions (Stenmark, 2009). Our NMR data revealed that Rab8a binds to $\alpha \mathrm{S}$ in both states, but with a slightly stronger affinity towards Rab8a(GDP) (Fig. 2). The interaction occurs between the C-terminus of $\alpha \mathrm{S}$ and the switch $1 / 2$ region of Rab8al (Fig. 3). The importance of the interaction with the switch $1 / 2$ region was supported by interaction studies employing a Rab8a variant lacking the C-terminal tail (Supplementary
Fig. S2). The switch $1 / 2$ region of Rab8a is predominantly positive and provides a favorable binding surface for the negatively charged C-terminal domain of $\alpha \mathrm{S}$ (Fig. 3E). Notably, the major structural change between the two nucleotide-bound states of Rab proteins occurs in this region with the GTP-bound state being more rigid (Itzen and Goody, 2011; Lee et al., 2009). Thus, different conformations of the switch region and in particular the G2 loop of Rab8a might contribute to the higher affinity of $\alpha \mathrm{S}$ towards Rab8a(GDP) (Fig. 2). The difference in affinity suggests that the GTP-bound state of Rab8a is less affected by overexpression of $\alpha \mathrm{S}$. On the other hand, GTP-bound Rab proteins interact with many effector proteins, while inactive Rab proteins are complexed with guanine nucleotide dissociation inhibitor proteins (Itzen and Goody, 2011). Thus, $\alpha$ S needs to compete with a variety of Rab8a binding partners. In addition, GTP-bound Rab proteins are anchored to membranes via a C-terminal lipid anchor (Hutagalung et al., 2009), and only leave the membrane upon hydrolysis to GDP. Thus, new interactions with the $\alpha$-helix of membrane-bound $\alpha S$ might arise in the GTP-bound membrane-anchored state of Rab8a. In line with its cytosolic state, however, we found a preferential interaction with GDP-

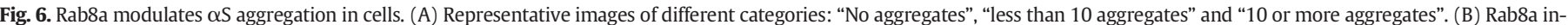

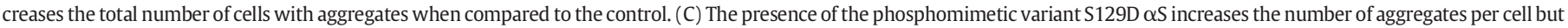

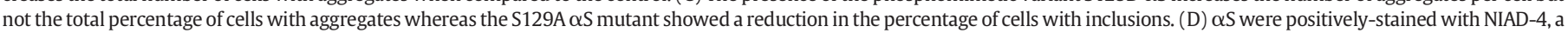
dye that recognizes beta-amyloid structure. Scale bar: $5 \mu \mathrm{m}$. 
A

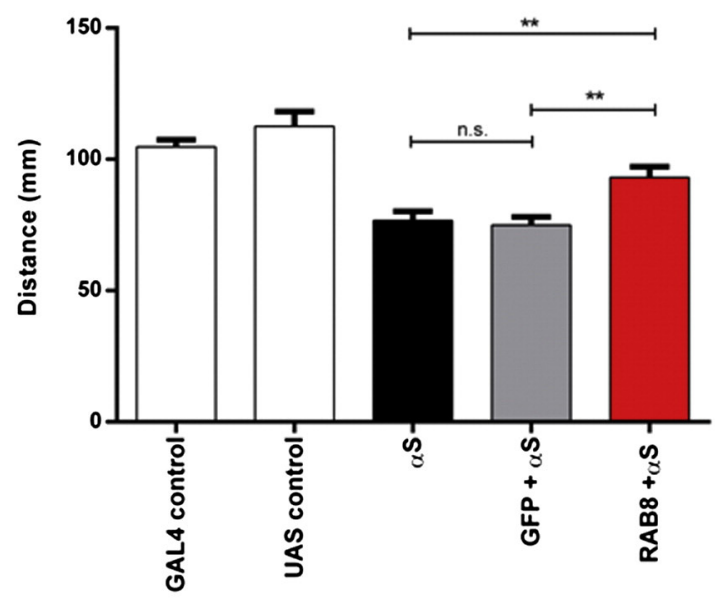

C

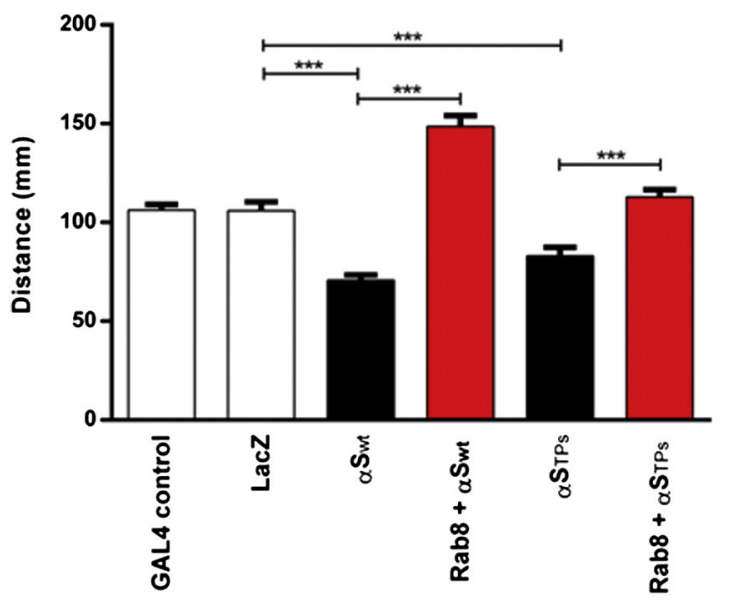

B

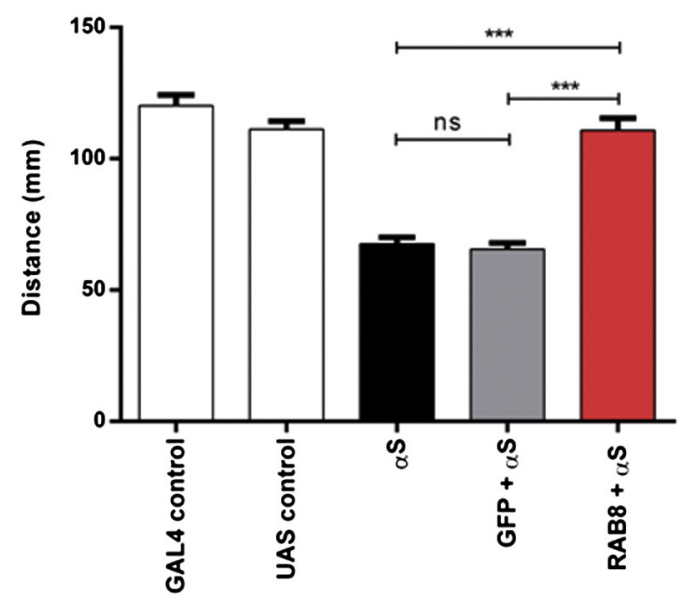

D

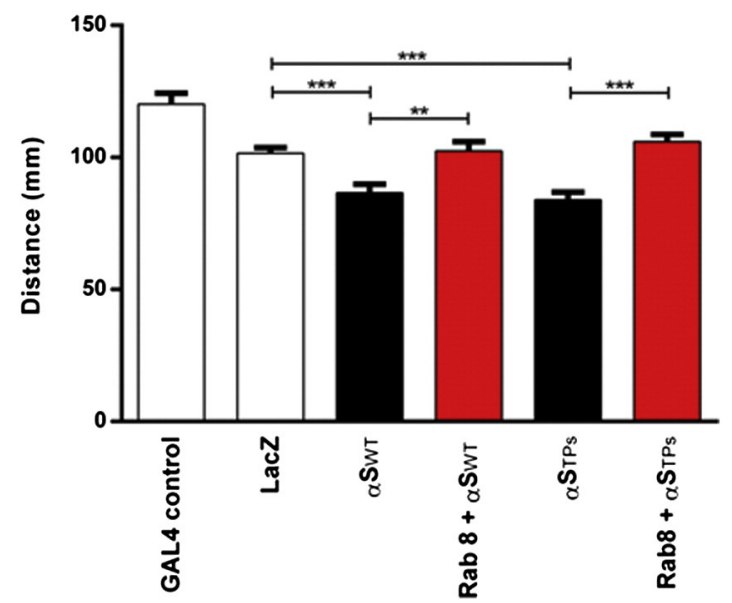

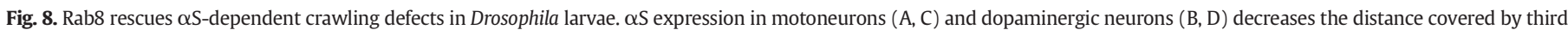

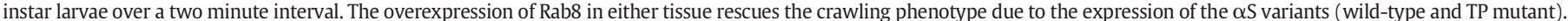
$\mathrm{N}=40$ for each genotype analyzed. Data are mean \pm S.E.M. ANOVA with post hoc tests. ${ }^{*} \mathrm{p}<0.05,{ }^{* *} \mathrm{p}<0.01,{ }^{* * *} \mathrm{p}<0.001$.

bound Rab8a in our in vitro measurements, which employed soluble Rab8a and $\alpha$ S. In addition, it is important to keep in mind that $\alpha S$ is highly abundant in neuronal systems (Jakes et al., 1994; Iwai et al., 1995) and a large excess of $\alpha S$ could favor binding to Rab8a. Indeed, triplication of the $\alpha$ S locus was shown to cause PD and $\alpha$ S progressively accumulates in cytosolic vesicles and the ER during disease (Cooper et al., 2006; Colla et al., 2012). Moreover, the C-terminal tail of Rab8a is less affected by nucleotide and membrane binding and can therefore - independent of other Rab8a interactions - contribute to the interaction with the C-terminal domain of $\alpha \mathrm{S}$, which remains accessible in both the soluble and membrane-bound states and even in $\alpha$ S fibrils (Del Mar et al., 2005; Eliezer et al., 2001; Ulmer et al., 2005; Vilar et al., 2008).

Aggregation of $\alpha \mathrm{S}$ into insoluble deposits is a hallmark of PD and is observed in cellular and animal models based on $\alpha \mathrm{S}$ overexpression (Chesselet, 2008). Understanding the underlying toxicity of different $\alpha \mathrm{S}$ species in the aggregation pathway has been a major goal in the field. Although current theories suggest that oligomeric species might constitute the most toxic species (Karpinar et al., 2009; Outeiro et al., 2008; Winner et al., 2011), consensus is still lacking (El-Agnaf et al., 1998; Tanik et al., 2013). An undisputable fact, obtained from the clinical research, is that intracellular aggregates are found in the surviving neurons of PD patients indicating that their presence can, perhaps, have a beneficial effect in cell survival (Forno, 1996). Our experiments show that overexpression of Rab8a in a cellular model increased the number of cells with $\alpha S$ inclusions (Fig. 6), in line with enhanced in vitro aggregation of $\alpha \mathrm{S}$ into amyloid fibrils in the presence of Rab8a (Fig. 5). In addition, we found that mimicking $\alpha$ S phosphorylation increased the number of inclusions per cell. NMR spectroscopy suggests that the enhanced aggregation is due to a direct binding of Rab8a to the $C$-terminus of $\alpha \mathrm{S}$ that has been implicated in interactions with a variety of protein partners (Burre et al., 2010; De Genst et al., 2010; Jensen et al., 1999, 2000; Kawamata et al., 2001; Kim et al., 2002; Yap et al., 2011). Thus, our study provides a link between physiological $\alpha$ S interactions and pathogenic aggregation. Moreover, Rab8a decreased $\alpha \mathrm{S}$ toxicity in our cell model while $\alpha S$ levels remained unchanged (Fig. 7), consistent with previous studies in which Rab8a was able to decrease $\alpha S$ associated neuronal loss in a C. elegans model and in rat primary neuronal cultures (Gitler et al., 2008). Our finding that Rab8 dramatically improved $\alpha$ S-dependent behavioral deficits in several Drosophila models (Figs. 8 and 9) further supports these observations. Thus, a Rab8a-mediated increase in formation of insoluble $\alpha S$ aggregates could constitute a mechanism underlying Rab8a-mediated cellular protection.

Phosphorylation of $\alpha S$ at S129 is the most abundant posttranslational modification in Lewy bodies (Anderson et al., 2006; 


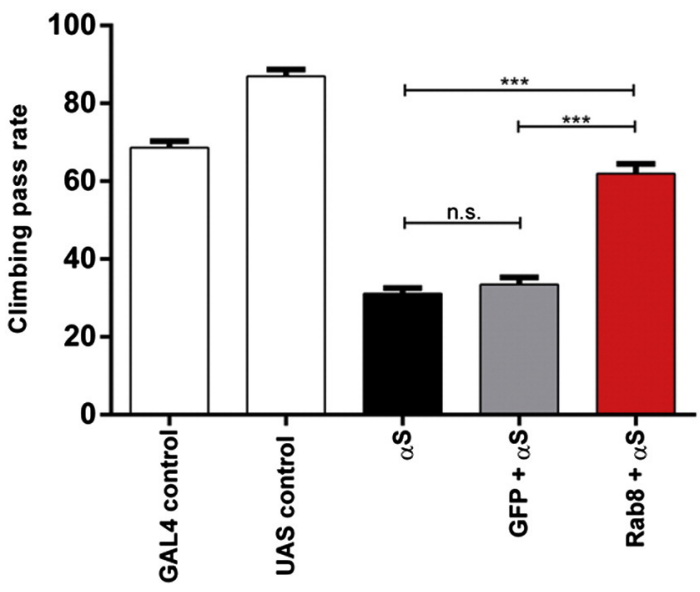

Fig. 9. Pan-neuronal expression of Rab8 rescues $\alpha$ S locomotor impairments. Expression of $\alpha S$ via elavGAL4 significantly reduces climbing activity of adult fruit flies at day 10 posteclosion, which is rescued by overexpression of Rab8. GFP $+\alpha$ S flies served as controls for possible titration effects. $\mathrm{N}=60$ for each genotype analyzed. Data are mean \pm S.E.M. ANOVA with post hoc tests. n.s. $=$ not significant, ${ }^{* * *} \mathrm{p}<0.001$.

Fujiwara et al., 2002). S129 can be phosphorylated by a variety of kinases in vitro and in vivo (Waxman and Giasson, 2010). In particular, polo-like kinases quantitatively and selectively phosphorylate $\alpha \mathrm{S}$ at S129 and levels of polo-like kinase 2 are increased in the brains of patients with Lewy body disease (Inglis et al., 2009; Mbefo et al., 2010). However, the relevance of $\alpha$ S phosphorylation at S129 for neurotoxicity and disease remains controversial (Basso et al., 2013). While some reports report a beneficial effect (Kuwahara et al., 2012; Oueslati et al., 2013), others identified deleterious consequences (Chen and Feany, 2005; Sato et al., 2011). A separate study found no effects of this posttranslational modification (McFarland et al., 2009). Our study reveals that phosphorylation of $\alpha \mathrm{S}$ at S129 enhances the binding of $\alpha \mathrm{S}$ to Rab8a (Fig. 4). This finding is in line with a previous observation that $\alpha \mathrm{S}$ phosphorylated at $\mathrm{S} 129$ is found specifically in pull downs with vesicular trafficking proteins (McFarland et al., 2008). Notably, the S129D variant of $\alpha$ S also showed enhanced Rab8a binding (Fig. 4), supporting its use for mimicking S129 phosphorylation in vivo. In addition, coexpression of S129D $\alpha \mathrm{S}$ with Rab8a enhanced aggregation of $\alpha \mathrm{S}$ in $\mathrm{H} 4$ cells to a larger degree than coexpression of wt $\alpha \mathrm{S}$ with Rab8a (Fig. 6C) and reduced cellular toxicity (Fig. 7A). In line with these findings, phosphorylation of $\alpha \mathrm{S}$ at S129 can - dependent on the genetic background - reduce $\alpha$ S-induced defects in vesicle trafficking (Sancenon et al., 2012). Thus, our study provides molecular insights into the functional consequences of phosphorylation of $\alpha \mathrm{S}$ at S129 and supports the role of changes in protein-protein interactions for $\alpha S$ pathogenicity (McFarland et al., 2008).

In summary, we have established a direct interaction between $\alpha S$ and Rab8a and provided unique insights into the molecular mechanisms of $\alpha$ S toxicity. Binding of $\alpha S$ to the switch $1 / 2$ region of Rab8a suggests that $\alpha \mathrm{S}$ can interfere with the physiological function of Rab GTPases, in particular when $\alpha$ S levels are increased, and thus lead to deficits in vesicle trafficking. Phosphorylation at S129 enhances binding of $\alpha$ S to Rab8a, increases aggregation of $\alpha S$ into insoluble aggregates and reduces $\alpha S$-induced cellular toxicity. S129 phosphorylation can therefore critically influence the toxic interplay of Rab8a and $\alpha$ S, further supporting the possibility of targeting phosphorylation as a therapeutic strategy in PD and other synucleinopathies.

\section{Abbreviations}

$\begin{array}{ll}\alpha S & \text { alpha-synuclein } \\ \text { EM } & \text { electron microscopy } \\ \text { ER } & \text { endoplasmic reticulum } \\ \text { GDP } & \text { guanosine diphosphate } \\ \text { GTP } & \text { guanosine triphosphate } \\ \text { GPpNHp } & \text { on-hydrolysable analog of GTP } \\ \text { HSQC } & \text { heteronuclear single-quantum coherence } \\ \text { LDH } & \text { lactate dehydrogenase } \\ \text { NMR } & \text { nuclear magnetic resonance } \\ \text { PD } & \text { Parkinson's disease } \\ \text { Rab } & \text { Ras related in brain } \\ \text { Rab8a-C } & \text { Rab8a (9-178) } \\ \text { SNARE } & \text { soluble NSF attachment protein receptor } \\ \text { ThT } & \text { Thioflavin T }\end{array}$

\section{Driver control $\square \alpha S_{W T} \square$ GFP $+\alpha S_{W T} \square R a b 8+\alpha S_{W T}$}
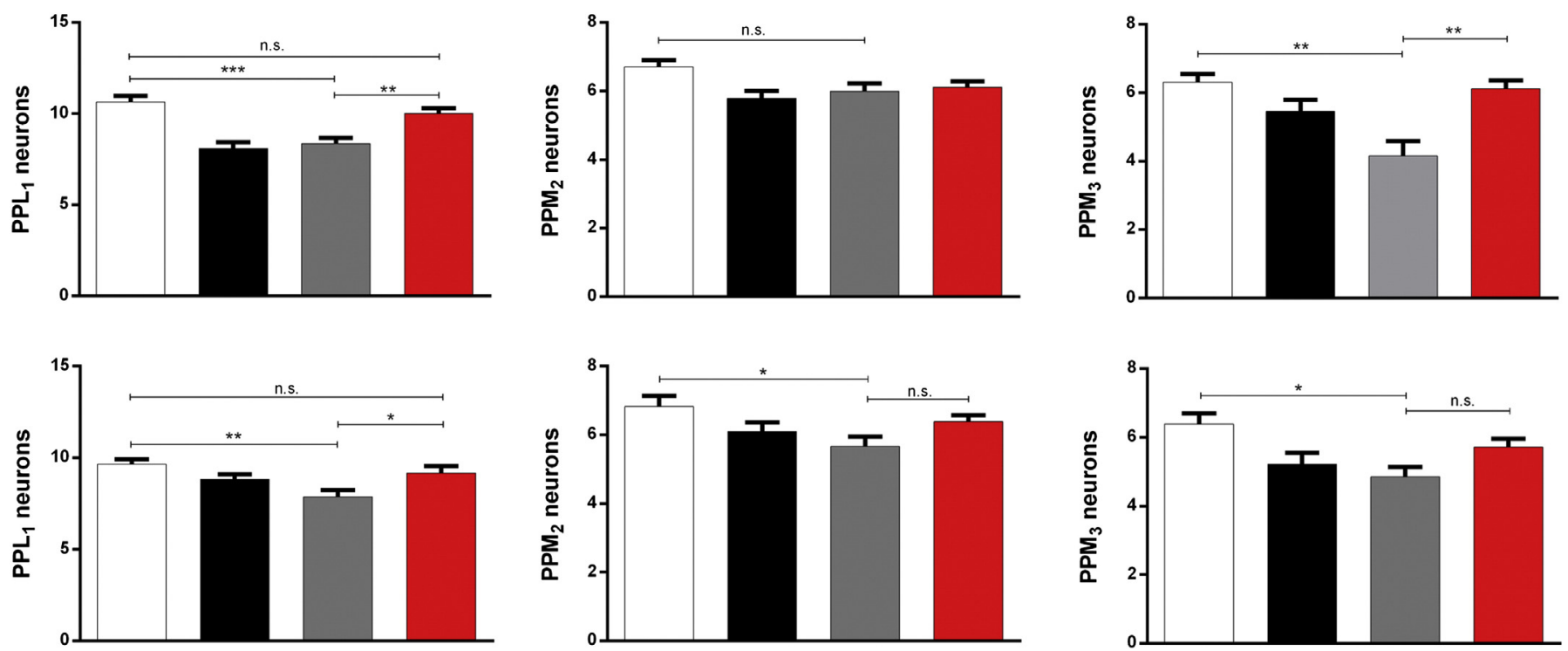

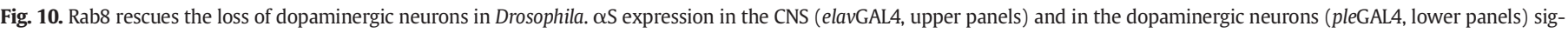

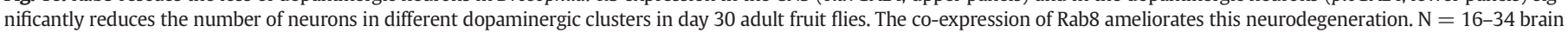
hemispheres per genotype. Data are mean \pm S.E.M. ANOVA with post hoc tests. n.s. $=$ not significant, ${ }^{*} \mathrm{p}<0.05,{ }^{* *} \mathrm{p}<0.01$ and ${ }^{* * *} \mathrm{p}<0.001$. 
Supplementary data to this article can be found online at http://dx. doi.org/10.1016/j.nbd.2014.06.018.

\section{Acknowledgments}

We thank Dr. Dietmar Riedel and Gudrun Heim for electron micrographs, Sebastian Wolff and Karin Giller for $\alpha$ S sample preparation, Kerstin Overkamp for peptide synthesis, Nathalie Bleimling for Rab8a sample preparation and Pinar Karpinar for help in initial NMR measurements. The GFP-Rab8a plasmid was kindly provided by Dr. Mikael Simons. This work was supported by the BMBF (NGFN-Plus 01GS08190 to M.Z.). Tomás Lopes da Fonseca is supported by a fellowship from the Fundação para a Ciência e a Tecnologia, Portugal (SFRH/BD/74881/ 2010). Work in the laboratory of Flaviano Giorgini is supported by Parkinson's UK (G-1203). TFO is supported by the DFG Center for Nanoscale Microscopy and Molecular Physiology of the Brain. The authors declare that they have no conflict of interest.

\section{References}

Abeliovich, A., et al., 2000. Mice lacking alpha-synuclein display functional deficits in the nigrostriatal dopamine system. Neuron 25, 239-252.

Ali, Y.O., Escala, W., Ruan, K., Zhai, R.G., 2011. Assaying locomotor, learning, and memory deficits in Drosophila models of neurodegeneration. J. Vis. Exp. http://dx.doi.org/10. 3791/2504 (2504 [pii]).

Anderson, J.P., et al., 2006. Phosphorylation of Ser-129 is the dominant pathological modification of alpha-synuclein in familial and sporadic Lewy body disease. J. Biol. Chem. 281, 29739-29752. http://dx.doi.org/10.1074/jbc.M600933200 (M600933200 [pii]).

Auluck, P.K., Caraveo, G., Lindquist, S., 2010. Alpha-synuclein: membrane interactions and toxicity in Parkinson's disease. Annu. Rev. Cell Dev. Biol. 26, 211-233. http://dx.doi. org/10.1146/annurev.cellbio.042308.113313.

Baker, N.A., Sept, D., Joseph, S., Holst, M.J., McCammon, J.A., 2001. Electrostatics of nanosystems: application to microtubules and the ribosome. Proc. Natl. Acad. Sci. U. S. A 98, 10037-10041. http://dx.doi.org/10.1073/pnas.181342398.

Basso, E., et al., 2013. PLK2 modulates alpha-synuclein aggregation in yeast and mammalian cells. Mol. Neurobiol. http://dx.doi.org/10.1007/s12035-013-8473-z.

Ben Gedalya, T., et al., 2009. Alpha-synuclein and polyunsaturated fatty acids promote clathrin-mediated endocytosis and synaptic vesicle recycling. Traffic 10, 218-234.

Bertoncini, C.W., et al., 2005. Release of long-range tertiary interactions potentiates aggregation of natively unstructured alpha-synuclein. Proc. Natl. Acad. Sci. U. S. A. 102, 1430-1435.

Bleimling, N., Alexandrov, K., Goody, R., Itzen, A., 2009. Chaperone-assisted production of active human Rab8A GTPase in Escherichia coli. Protein Expr. Purif. 65, 190-195.

Bodner, C.R., Dobson, C.M., Bax, A., 2009. Multiple tight phospholipid-binding modes of alpha-synuclein revealed by solution NMR spectroscopy. J. Mol. Biol. 390, 775-790.

Braak, H., et al., 2003. Staging of brain pathology related to sporadic Parkinson's disease. Neurobiol. Aging 24, 197-211.

Burre, J., et al., 2010. Alpha-synuclein promotes SNARE-complex assembly in vivo and in vitro. Science 329, 1663-1667. http://dx.doi.org/10.1126/science.1195227.

Butterfield, S.M., Lashuel, H.A., 2010. Amyloidogenic protein-membrane interactions: mechanistic insight from model systems. Angew. Chem. Int. Ed. 49, 5628-5654.

Cabin, D.E., et al., 2002. Synaptic vesicle depletion correlates with attenuated synaptic responses to prolonged repetitive stimulation in mice lacking alpha-synuclein. J. Neurosci. 22, 8797-8807.

Caughey, B., Lansbury, P.T., 2003. Protofibrils, pores, fibrils, and neurodegeneration: separating the responsible protein aggregates from the innocent bystanders. Annu. Rev. Neurosci. 26, 267-298.

Chandra, S., Gallardo, G., Fernandez-Chacon, R., Schluter, O.M., Sudhof, T.C., 2005. Alphasynuclein cooperates with CSPalpha in preventing neurodegeneration. Cell 123, 383-396.

Chartier-Harlin, M.C., et al., 2004. Alpha-synuclein locus duplication as a cause of familial Parkinson's disease. Lancet 364, 1167-1169. http://dx.doi.org/10.1016/S01406736(04)17103-1.

Chen, L., Feany, M.B., 2005. Alpha-synuclein phosphorylation controls neurotoxicity and inclusion formation in a Drosophila model of Parkinson disease. Nat. Neurosci. 8, 657-663. http://dx.doi.org/10.1038/nn1443.

Chen, R.H., et al., 2013. Alpha-synuclein membrane association is regulated by the Rab3a recycling machinery and presynaptic activity. J. Biol. Chem. http://dx.doi.org/10. 1074/jbc.M112.439497 (M112.439497 [pii]).

Chesselet, M.F., 2008. In vivo alpha-synuclein overexpression in rodents: a useful model of Parkinson's disease? Exp. Neurol. 209, 22-27. http://dx.doi.org/10.1016/j. expneurol.2007.08.006 (S0014-4886(07)00307-X [pii]).

Choi, S.W., Gerencser, A.A., Nicholls, D.G., 2009. Bioenergetic analysis of isolated cerebrocortical nerve terminals on a microgram scale: spare respiratory capacity and stochastic mitochondrial failure. J. Neurochem. 109, 1179-1191. http://dx.doi. org/10.1111/j.1471-4159.2009.06055.x (JNC6055 [pii]).

Chung, C.Y., Koprich, J.B., Hallett, P.J., Isacson, O., 2009. Functional enhancement and protection of dopaminergic terminals by RAB3B overexpression. Proc. Natl. Acad. Sci. U. S. A. 106, 22474-22479.
Colla, E., et al., 2012. Accumulation of toxic alpha-synuclein oligomer within endoplasmic reticulum occurs in alpha-synucleinopathy in vivo. J. Neurosci. 32, 3301-3305. http://dx.doi.org/10.1523/JNEUROSCI.5368-11.2012 (32/10/3301 [pii]).

Cookson, M.R., 2009. Alpha-synuclein and neuronal cell death. Mol. Neurodegener. 4, 9.

Cooper, A.A., et al., 2006. Alpha-synuclein blocks ER-Golgi traffic and Rab1 rescues neuron loss in Parkinson's models. Science 313, 324-328. http://dx.doi.org/10.1126/science. 1129462 (1129462 [pii]).

Craik, D.J., Wilce, J.A., 1997. Studies of protein-ligand interactions by NMR. Methods Mol Biol. 60, 195-232.

Dalfo, E., Ferrer, I., 2005. Alpha-synuclein binding to rab3a in multiple system atrophy Neurosci. Lett. 380, 170-175. http://dx.doi.org/10.1016/j.neulet.2005.01.034 (S0304-3940(05)00073-X [pii]).

Dalfo, E., Barrachina, M., Rosa, J.L., Ambrosio, S., Ferrer, I., 2004a. Abnormal alphasynuclein interactions with rab3a and rabphilin in diffuse Lewy body disease. Neurobiol. Dis. 16, 92-97.

Dalfo, E., et al., 2004b. Abnormal alpha-synuclein interactions with Rab proteins in alphasynuclein A30P transgenic mice. J. Neuropathol. Exp. Neurol. 63, 302-313.

De Genst, E.J., et al., 2010. Structure and properties of a complex of alpha-synuclein and a single-domain camelid antibody. J. Mol. Biol. 402, 326-343. http://dx.doi.org/10. 1016/j.jmb.2010.07.001 (S0022-2836(10)00742-4 [pii]).

Dedmon, M.M., Lindorff-Larsen, K., Christodoulou, J., Vendruscolo, M., Dobson, C.M., 2005. Mapping long-range interactions in alpha-synuclein using spin-label NMR and ensemble molecular dynamics simulations. J. Am. Chem. Soc. 127, 476-477.

Del Mar, C., Greenbaum, E.A., Mayne, L., Englander, S.W., Woods Jr., V.L., 2005. Structure and properties of alpha-synuclein and other amyloids determined at the amino acid level. Proc. Natl. Acad. Sci. U. S. A. 102, 15477-15482. http://dx.doi.org/10. 1073/pnas.0507405102 (0507405102 [pii]).

El-Agnaf, O.M., et al., 1998. Aggregates from mutant and wild-type alpha-synuclein proteins and NAC peptide induce apoptotic cell death in human neuroblastoma cells by formation of beta-sheet and amyloid-like filaments. FEBS Lett. 440, 71-75.

Eliezer, D., Kutluay, E., Bussell Jr., R., Browne, G., 2001. Conformational properties of alpha-synuclein in its free and lipid-associated states. J. Mol. Biol. 307, 1061-1073. http://dx.doi.org/10.1006/jmbi.2001.4538 (S0022-2836(01)94538-3 [pii]).

Feany, M.B., Bender, W.W., 2000. A Drosophila model of Parkinson's disease. Nature 404 394-398. http://dx.doi.org/10.1038/35006074 (35006074 [pii]).

Fernandez, C.O., et al., 2004. NMR of alpha-synuclein-polyamine complexes elucidates the mechanism and kinetics of induced aggregation. EMBO J. 23, 2039-2046.

Forno, L.S., 1996. Neuropathology of Parkinson's disease. J. Neuropathol. Exp. Neurol. 55 259-272.

Fujiwara, H., et al., 2002. Alpha-synuclein is phosphorylated in synucleinopathy lesions Nat. Cell Biol. 4, 160-164.

Gajula Balija, M.B., Griesinger, C., Herzig, A., Zweckstetter, M., Jackle, H., 2011. Pre-fibrillar alpha-synuclein mutants cause Parkinson's disease-like non-motor symptoms in Drosophila. PLoS ONE 6, e24701. http://dx.doi.org/10.1371/journal.pone.0024701 (PONE-D-11-06498 [pii]).

Gitler, A.D., et al., 2008. The Parkinson's disease protein alpha-synuclein disrupts cellular Rab homeostasis. Proc. Natl. Acad. Sci. U. S. A. 105, 145-150. http://dx.doi.org/10. 1073/pnas.0710685105 (0710685105 [pii]).

Goers, J., Uversky, V.N., Fink, A.L., 2003. Polycation-induced oligomerization and accelerated fibrillation of human alpha-synuclein in vitro. Protein Sci. 12, 702-707. http://dx. doi.org/10.1110/ps.0230903.

Hardy, J., Lewis, P., Revesz, T., Lees, A., Paisan-Ruiz, C., 2009. The genetics of Parkinson's syndromes: a critical review. Curr. Opin. Genet. Dev. 19, 254-265. http://dx.doi.org/ 10.1016/j.gde.2009.03.008 (S0959-437X(09)00055-0 [pii]).

Henry, L., Sheff, D.R., 2008. Rab8 regulates basolateral secretory, but not recycling, traffic at the recycling endosome. Mol. Biol. Cell 19, 2059-2068. http://dx.doi.org/10.1091/ mbc.E07-09-0902 (E07-09-0902 [pii]).

Hou, X., et al., 2011. A structural basis for Lowe syndrome caused by mutations in the Rab-binding domain of OCRL1. EMBO J. 30, 1659-1670. http://dx.doi.org/10.1038/ emboj.2011.60 (emboj201160 [pii]).

Hoyer, W., et al., 2002. Dependence of alpha-synuclein aggregate morphology on solution conditions. J. Mol. Biol. 322, 383-393.

Hoyer, W., Cherny, D., Subramaniam, V., Jovin, T.M., 2004. Impact of the acidic C-terminal region comprising amino acids 109-140 on alpha-synuclein aggregation in vitro. Biochemistry 43, 16233-16242.

Hutagalung, A.H., Coleman, J., Pypaert, M., Novick, P.J., 2009. An internal domain of Exo70p is required for actin-independent localization and mediates assembly of specific exocyst components. Mol. Biol. Cell 20, 153-163. http://dx.doi.org/10.1091/mbc. E08-02-0157 (E08-02-0157 [pii]).

Inglis, K.J., et al., 2009. Polo-like kinase 2 (PLK2) phosphorylates alpha-synuclein at serine 129 in central nervous system. J. Biol. Chem. 284, 2598-2602. http://dx.doi.org/10. 1074/jbc.C800206200 (C800206200 [pii]).

Itzen, A., Goody, R.S., 2011. GTPases involved in vesicular trafficking: structures and mechanisms. Semin. Cell Dev. Biol. 22, 48-56.

Iwai, A., et al., 1995. The precursor protein of non-A beta component of Alzheimer's disease amyloid is a presynaptic protein of the central nervous system. Neuron 14 467-475 (0896-6273(95)90302-X [pii]).

Jakes, R., Spillantini, M.G., Goedert, M., 1994. Identification of two distinct synucleins from human brain. FEBS Lett. 345, 27-32 (0014-5793(94)00395-5 [pii]).

Jensen, P.H., et al., 1999. Alpha-synuclein binds to Tau and stimulates the protein kinase A-catalyzed tau phosphorylation of serine residues 262 and 356. J. Biol. Chem. 274 25481-25489.

Jensen, P.H., et al., 2000. Microtubule-associated protein 1B is a component of cortical Lewy bodies and binds alpha-synuclein filaments. J. Biol. Chem. 275, 21500-21507. http://dx.doi.org/10.1074/jbc.M000099200 (M000099200 [pii]). 
Jung, Y.S., Zweckstetter, M., 2004a. Mars - robust automatic backbone assignment of proteins. J. Biomol. NMR 30, 11-23.

Jung, Y.S., Zweckstetter, M., 2004b. Backbone assignment of proteins with known structure using residual dipolar couplings. J. Biomol. NMR 30, 25-35.

Karpinar, D.P., et al., 2009. Pre-fibrillar alpha-synuclein variants with impaired betastructure increase neurotoxicity in Parkinson's disease models. EMBO J. 28, 3256-3268. http://dx.doi.org/10.1038/emboj.2009.257.

Kawamata, H., McLean, P.J., Sharma, N., Hyman, B.T., 2001. Interaction of alpha-synuclein and synphilin-1: effect of Parkinson's disease-associated mutations. J. Neurochem. 77, 929-934.

Kim, T.D., Paik, S.R., Yang, C.H., 2002. Structural and functional implications of C-terminal regions of alpha-synuclein. Biochemistry 41, 13782-13790.

Kuwahara, T., et al., 2008. A systematic RNAi screen reveals involvement of endocytic pathway in neuronal dysfunction in alpha-synuclein transgenic C. elegans. Hum. Mol. Genet. 17, 2997-3009. http://dx.doi.org/10.1093/hmg/ddn198 (ddn198 [pii]).

Kuwahara, T., Tonegawa, R., Ito, G., Mitani, S., Iwatsubo, T., 2012. Phosphorylation of alpha-synuclein protein at Ser-129 reduces neuronal dysfunction by lowering its membrane binding property in Caenorhabditis elegans. J. Biol. Chem. 287, 7098-7109. http://dx.doi.org/10.1074/jbc.M111.237131.

Larsen, K.E., et al., 2006. Alpha-synuclein overexpression in PC12 and chromaffin cells impairs catecholamine release by interfering with a late step in exocytosis. J. Neurosci. 26, 11915-11922.

Lashuel, H.A., Hartley, D., Petre, B.M., Walz, T., Lansbury Jr., P.T., 2002. Neurodegenerative disease: amyloid pores from pathogenic mutations. Nature 418, 291.

Lashuel, H.A., Overk, C.R., Oueslati, A., Masliah, E., 2013. The many faces of alphasynuclein: from structure and toxicity to therapeutic target. Nat. Rev. Neurosci. 14, 38-48. http://dx.doi.org/10.1038/nrn3406 (nrn3406 [pii]).

Lee, M.T., Mishra, A., Lambright, D.G., 2009. Structural mechanisms for regulation of membrane traffic by rab GTPases. Traffic 10, 1377-1389.

Levitan, K., et al., 2011. Conserved C-terminal charge exerts a profound influence on the aggregation rate of alpha-synuclein. J. Mol. Biol. 411, 329-333.

Liu, S., et al., 2004. Alpha-synuclein produces a long-lasting increase in neurotransmitter release. EMBO J. 23, 4506-4516.

Liu, J., et al., 2009. Rab11a and HSP90 regulate recycling of extracellular alpha-synuclein. J. Neurosci. 29, 1480-1485.

London, N., Raveh, B., Cohen, E., Fathi, G., Schueler-Furman, O., 2011. Rosetta FlexPepDock web server-high resolution modeling of peptide-protein interactions. Nucleic Acids Res. 39, W249-W253. http://dx.doi.org/10.1093/nar/gkr431.

Marques, O., Outeiro, T.F., 2012. Alpha-synuclein: from secretion to dysfunction and death. Cell Death Dis. 3, e350. http://dx.doi.org/10.1038/cddis.2012.94 (cddis201294 [pii]).

Mbefo, M.K., et al., 2010. Phosphorylation of synucleins by members of the polo-like kinase family. J. Biol. Chem. 285, 2807-2822.

McFarland, M.A., Ellis, C.E., Markey, S.P., Nussbaum, R.L., 2008. Proteomics analysis identifies phosphorylation-dependent alpha-synuclein protein interactions. Mol. Cell. Proteomics 7, 2123-2137. http://dx.doi.org/10.1074/mcp.M800116-MCP200 (M800116-MCP200 [pii]).

McFarland, N.R., et al., 2009. Alpha-synuclein S129 phosphorylation mutants do not alter nigrostriatal toxicity in a rat model of Parkinson disease. J. Neuropathol. Exp. Neurol. 68, 515-524. http://dx.doi.org/10.1097/NEN.0b013e3181a24b53.

McLean, P.J., Kawamata, H., Hyman, B.T., 2001. Alpha-synuclein-enhanced green fluorescent protein fusion proteins form proteasome sensitive inclusions in primary neurons. Neuroscience 104, 901-912 (S0306-4522(01)00113-0 [pii]).

Murphy, D.D., Rueter, S.M., Trojanowski, J.Q., Lee, V.M., 2000. Synucleins are developmentally expressed, and alpha-synuclein regulates the size of the presynaptic vesicular pool in primary hippocampal neurons. J. Neurosci. 20, 3214-3220.

Nakamura, S., Kawamoto, Y., Nakano, S., Akiguchi, I., 2000. Expression of the endocytosis regulatory proteins Rab5 and Rabaptin-5 in glial cytoplasmic inclusions from brains with multiple system atrophy. Clin. Neuropathol. 19, 51-56.

Nowicki Jr., S., Oxenford, C., 1989. The relation of hostile nonverbal communication styles to popularity in preadolescent children. J. Genet. Psychol. 150, 39-43. http://dx.doi. org/10.1080/00221325.1989.9914572.

Olzscha, H., et al., 2011. Amyloid-like aggregates sequester numerous metastable proteins with essential cellular functions. Cell 144, 67-78. http://dx.doi.org/10.1016/j.cell. 2010.11.050.

Oueslati, A., Fournier, M., Lashuel, H.A., 2010. Role of post-translational modifications in modulating the structure, function and toxicity of alpha-synuclein: implications for Parkinson's disease pathogenesis and therapies. Prog. Brain Res. 183, 115-145.
Oueslati, A., Schneider, B.L., Aebischer, P., Lashuel, H.A., 2013. Polo-like kinase 2 regulates selective autophagic alpha-synuclein clearance and suppresses its toxicity in vivo. Proc. Natl. Acad. Sci. U. S. A. 110, E3945-E3954. http://dx.doi.org/10.1073/pnas. 1309991110

Outeiro, T.F., et al., 2008. Formation of toxic oligomeric alpha-synuclein species in living cells. PLoS ONE 3, e1867. http://dx.doi.org/10.1371/journal.pone.0001867.

Pienaar, I.S., Gotz, J., Feany, M.B., 2010. Parkinson's disease: insights from non-traditional model organisms. Prog. Neurobiol. 92, 558-571. http://dx.doi.org/10.1016/j. pneurobio.2010.09.001 (S0301-0082(10)00159-0 [pii]).

Polymeropoulos, M.H., et al., 1997. Mutation in the alpha-synuclein gene identified in families with Parkinson's disease. Science 276, 2045-2047.

Qin, Z., Hu, D., Han, S., Hong, D.P., Fink, A.L., 2007. Role of different regions of alphasynuclein in the assembly of fibrils. Biochemistry 46, 13322-13330. http://dx.doi. org/10.1021/bi7014053.

Raveh, B., London, N., Schueler-Furman, O., 2010. Sub-angstrom modeling of complexes between flexible peptides and globular proteins. Proteins 78, 2029-2040. http://dx. doi.org/10.1002/prot.22716.

Rendon, W.O., Martinez-Alonso, E., Tomas, M., Martinez-Martinez, N., MartinezMenarguez, J.A., 2013. Golgi fragmentation is Rab and SNARE dependent in cellular models of Parkinson's disease. Histochem. Cell Biol. 139, 671-684. http://dx.doi.org/ 10.1007/s00418-012-1059-4.

Sancenon, V., et al., 2012. Suppression of alpha-synuclein toxicity and vesicle trafficking defects by phosphorylation at S129 in yeast depends on genetic context. Hum Mol Genet 21, 2432-2449. http://dx.doi.org/10.1093/hmg/dds058 (dds058 [pii]).

Sato, H., et al., 2011. Authentically phosphorylated alpha-synuclein at Ser129 accelerates neurodegeneration in a rat model of familial Parkinson's disease. J. Neurosci. 31, 16884-16894. http://dx.doi.org/10.1523/JNEUROSCI.3967-11.2011.

Sato, H., Kato, T., Arawaka, S., 2013. The role of Ser129 phosphorylation of alpha-synuclein in neurodegeneration of Parkinson's disease: a review of in vivo models. Rev. Neurosci. 1-9. http://dx.doi.org/10.1515/revneuro-2012-0071 (/j/revneuro.aheadof-print/revneuro-2012-0071/revneuro-2012-0071.xml [pii]).

Soper, J.H., et al., 2008. Alpha-synuclein-induced aggregation of cytoplasmic vesicles in Saccharomyces cerevisiae. Mol. Biol. Cell 19, 1093-1103. http://dx.doi.org/10.1091/ mbc.E07-08-0827 (E07-08-0827 [pii]).

Soper, J.H., Kehm, V., Burd, C.G., Bankaitis, V.A., Lee, V.M., 2011. Aggregation of alphasynuclein in S. cerevisiae is associated with defects in endosomal trafficking and phospholipid biosynthesis. J. Mol. Neurosci. 43, 391-405.

Spillantini, M.G., et al., 1997. Alpha-synuclein in Lewy bodies. Nature 388, 839-840. http://dx.doi.org/10.1038/42166.

Steinert, J.R., et al., 2012. Rab11 rescues synaptic dysfunction and behavioural deficits in a Drosophila model of Huntington's disease. Hum. Mol. Genet. 21, 2912-2922. http:// dx.doi.org/10.1093/hmg/dds117.

Stenmark, H. Rab, 2009. GTPases as coordinators of vesicle traffic. Nat. Rev. Mol. Cell Biol. 10, 513-525. http://dx.doi.org/10.1038/nrm2728 nrm2728 (pii).

Sung, J.Y., et al., 2001. Induction of neuronal cell death by Rab5A-dependent endocytosis of alpha-synuclein. J. Biol. Chem. 276, 27441-27448. http://dx.doi.org/10.1074/jbc. M101318200 (M101318200 [pii]).

Tanik, S.A., Schultheiss, C.E., Volpicelli-Daley, L.A., Brunden, K.R., Lee, V.M., 2013. Lewy body-like alpha-synuclein aggregates resist degradation and impair macroautophagy. J. Biol. Chem. 288, 15194-15210. http://dx.doi.org/10.1074/jbc.M113.457408.

Ulmer, T.S., Bax, A., Cole, N.B., Nussbaum, R.L., 2005. Structure and dynamics of micellebound human alpha-synuclein. J. Biol. Chem. 280, 9595-9603. http://dx.doi.org/10. 1074/jbc.M411805200 (M411805200 [pii]).

Vilar, M., et al., 2008. The fold of alpha-synuclein fibrils. Proc. Natl. Acad. Sci. U. S. A. 105, 8637-8642. http://dx.doi.org/10.1073/pnas.0712179105 (0712179105 [pii]).

Waxman, E.A., Giasson, B.I., 2009. Molecular mechanisms of alpha-synuclein neurodegeneration. Biochim. Biophys. Acta 1792, 616-624. http://dx.doi.org/10.1016/j.bbadis. 2008.09.013 (S0925-4439(08)00188-9 [pii]).

Waxman, E.A., Giasson, B.I., 2010. Characterization of kinases involved in the phosphorylation of aggregated alpha-synuclein. J. Neurosci. Res. 89, 231-247. http://dx.doi.org/ 10.1002/jnr.22537.

Winner, B., et al., 2011. In vivo demonstration that alpha-synuclein oligomers are toxic. Proc. Natl. Acad. Sci. U. S. A. 108, 4194-4199. http://dx.doi.org/10.1073/pnas.1100976108.

Wu, K.P., Baum, J., 2010. Detection of transient interchain interactions in the intrinsically disordered protein alpha-synuclein by NMR paramagnetic relaxation enhancement. J. Am. Chem. Soc. 132, 5546-5547. http://dx.doi.org/10.1021/ja9105495.

Yap, T.L., et al., 2011. Alpha-synuclein interacts with glucocerebrosidase providing a molecular link between Parkinson and Gaucher diseases. J. Biol. Chem. 286, 28080-28088. http://dx.doi.org/10.1074/jbc.M111.237859 (M111.237859 [pii]). 